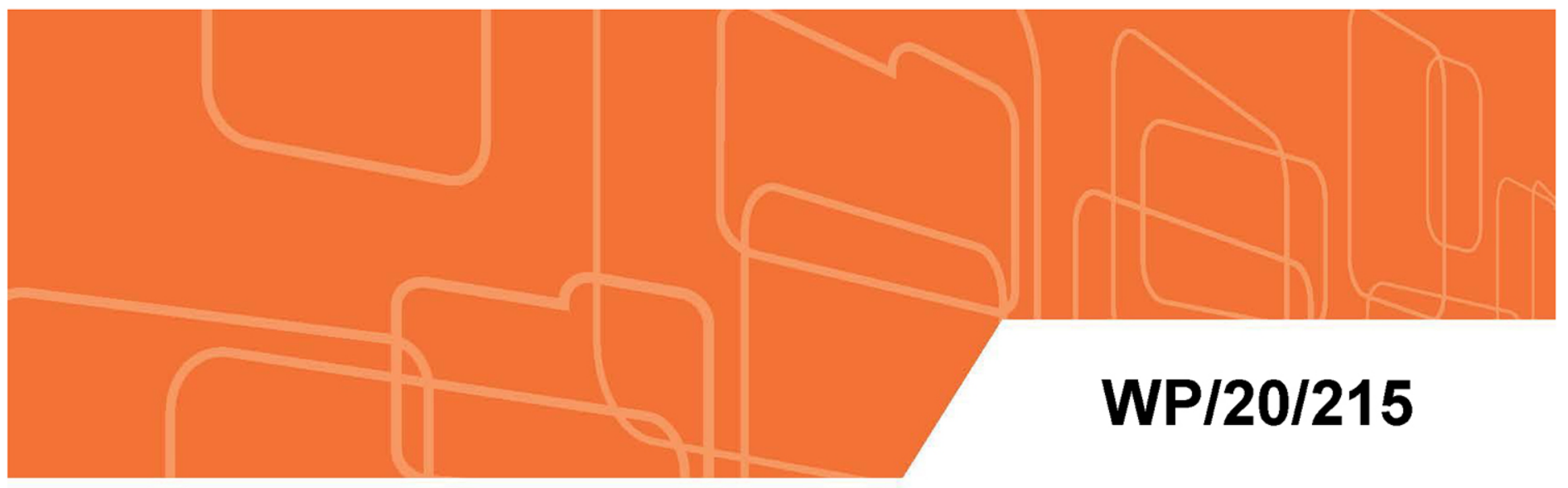

IMF Working Paper

\title{
Mexico Needs A Fiscal Twist: Response to Covid-19 and Beyond
}

by Swarnali Ahmed Hannan, Keiko Honjo, Mehdi Raissi

IMF Working Papers describe research in progress by the author(s) and are published to elicit comments and to encourage debate. The views expressed in IMF Working Papers are those of the author(s) and do not necessarily represent the views of the IMF, its Executive Board, or IMF management. 


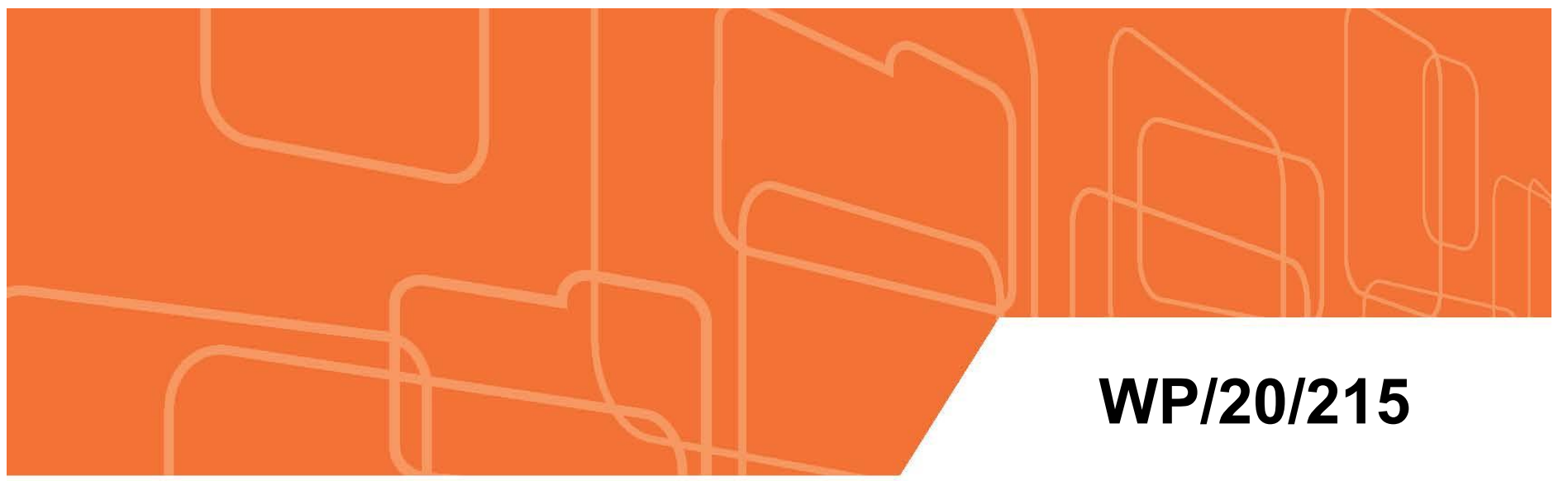

\section{IMF Working Paper}

\section{Mexico Needs A Fiscal Twist: Response to Covid-19 and Beyond}

by Swarnali Ahmed Hannan, Keiko Honjo, Mehdi Raissi

IMF Working Papers describe research in progress by the author(s) and are published to elicit comments and to encourage debate. The views expressed in IMF Working Papers are those of the author(s) and do not necessarily represent the views of the IMF, its Executive Board, or IMF management. 


\title{
IMF Working Paper
}

Western Hemisphere Department

Mexico Needs a Fiscal Twist: Response to Covid-19 and Beyond

Prepared by Swarnali Ahmed Hannan, Keiko Honjo, Mehdi Raissi

Authorized for distribution by Rishi Goyal

October 2020

IMF Working Papers describe research in progress by the author(s) and are published to elicit comments and to encourage debate. The views expressed in IMF Working Papers are those of the author(s) and do not necessarily represent the views of the IMF, its Executive Board, or IMF management.

\begin{abstract}
Mexico's fiscal response to the pandemic has been modest compared to its peers, reflecting the authorities' desire to not issue new debt for spending. This approach, however, risks a more severe recession and a weaker economic recovery, with further costs in the future. Balancing the need for stronger near-term fiscal support for the people and the recovery against medium-term discipline, this paper lays out an alternative strategy. We show that credibly announcing a pro-growth and inclusive medium-term fiscal reform upfrontincluding increased tax capacity, higher public investment and strengthened social safety nets - would open space for larger short-term support and close medium-term fiscal gaps. Model simulations suggest that this package would boost output, limit lasting economic damage from the pandemic, and put debt trajectory on a declining path in the medium term as tax reforms pay off and risk premia decline.
\end{abstract}

JEL Classification Numbers: H2, H5, H6, E2, E6.

Keywords: Covid-19, fiscal response, tax, social safety nets, general equilibrium model.

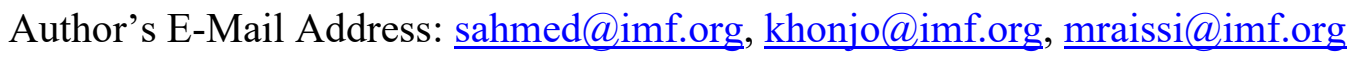




\section{INTRODUCTION ${ }^{1}$}

Mexico's fiscal response to the Covid-19 shock has been modest. Thus far, additional expenditures have amounted to 0.2 percent of GDP to support health care and 0.5 percent of GDP to protect households and firms (see Box 1 for details). Loans to formal workers and recently laid-off employees as well as contingent liabilities added up to 0.5 percent of GDP. As illustrated in Figure 1, the level of support is significantly lower than the peers in Latin America and the G20, and may lead to economic scarring. The size of spending and revenue measures in 2020 is also smaller than the announced discretionary fiscal stimulus in 2009 (Figure 2), which included public investment and targeted transfers.

Figure 1. Fiscal Measures in Response to the Covid-19 Pandemic (Percent of GDP)

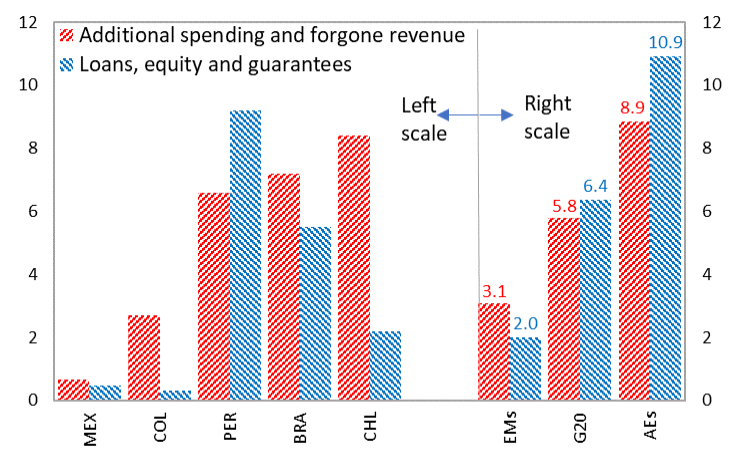

Sources: National authorities and IMF staff estimates. Note: Weighted by GDP in PPP-adjusted current US dollars for country groups. Revenue and spending measures exclude deferred taxes and advance payments. See Fiscal Monitor Database of Covid19 Measures for details.
Figure 2. Emergency Lifelines in 2020 versus Announced Discretionary Stimulus in 2009 (Percent of GDP)

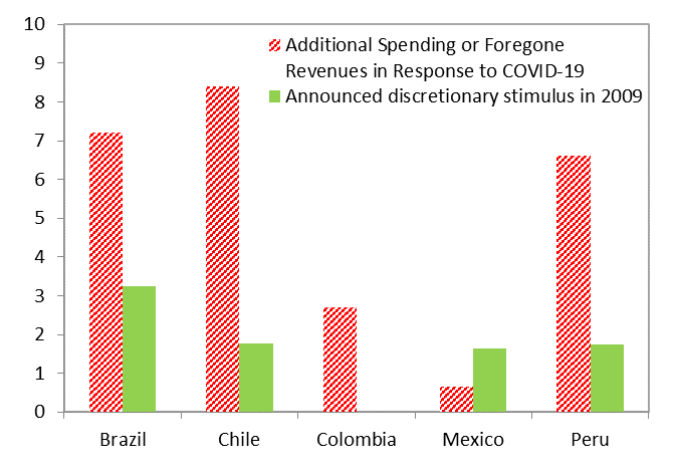

Source: FM Measures Database and SDN/15/06.

Unlike a typical macroeconomic disturbance, the Covid-19 pandemic and policies implemented to contain its spread have brought about simultaneous disruptions to demand and supply in a totally new economic environment. Chudik and others (2020) quantify the economic impact of the pandemic on various countries/regions and show that these effects could be long-lasting without decisive policy actions. They highlight the importance of policy interventions that can restore the normal functioning of financial markets, as well as adopting fiscal measures that can limit bankruptcies of viable firms and support incomes of households. Similarly, IMF (2020a) shows that the announced fiscal policy measures in Latin America and the Caribbean are playing an important role in mitigating the effects of the pandemic. Moreover, Deb and others (2020) find that while containment measures have led to a large impact on economic activity, fiscal and monetary policy measures used in response to the crisis were effective in mitigating some of these economic costs.

\footnotetext{
${ }^{1}$ The authors would like to thank Rishi Goyal for his overall guidance; Juan Pablo Cuesta Aguirre for excellent research assistance; Javier Ochoa for excellent editorial assistance; Krishna Srinivasan, Alejandro Werner, Nikolay Gueorguiev, Michael Perks, Francisco Roldan, Saji Thomas, and colleagues from IMF, Secretaría de Hacienda y Crédito Público (SHCP, Mexico) and Banco de México for their helpful suggestions and comments.
} 
To evaluate the case for fiscal action, it is helpful to consider three phases of the Covid-19 pandemic (Figure 3). The first is the acute phase in which lockdowns are fully in place. The role of fiscal policy in this stage is to save lives and livelihoods by relying on three levers (see IMF 2020b for details): (1) fully accommodating spending on health care; (2) providing emergency lifelines ${ }^{2}$ to households and firms to cushion the adverse impact of lockdowns, including in hard-to-reach informal sectors; and (3) letting automatic stabilizers operate, especially unemployment benefits and social safety nets. The second phase is when lockdowns are gradually lifted under uncertainty about the course of the Covid-19 pandemic and the economy. In this phase, the role of fiscal policy is to gradually unwind emergency lifelines while strengthening social safety nets in a more durable way, supporting the resumption of economic activity, lifting demand with fiscal stimulus, and, if needed, facilitating a reallocation of resources (rather than saving unviable firms). The final phase is when pharmaceutical interventions and medical treatments are widely available, and the pandemic is under control. In this period, fiscal space should be re-built through growthfriendly and inclusive adjustments.

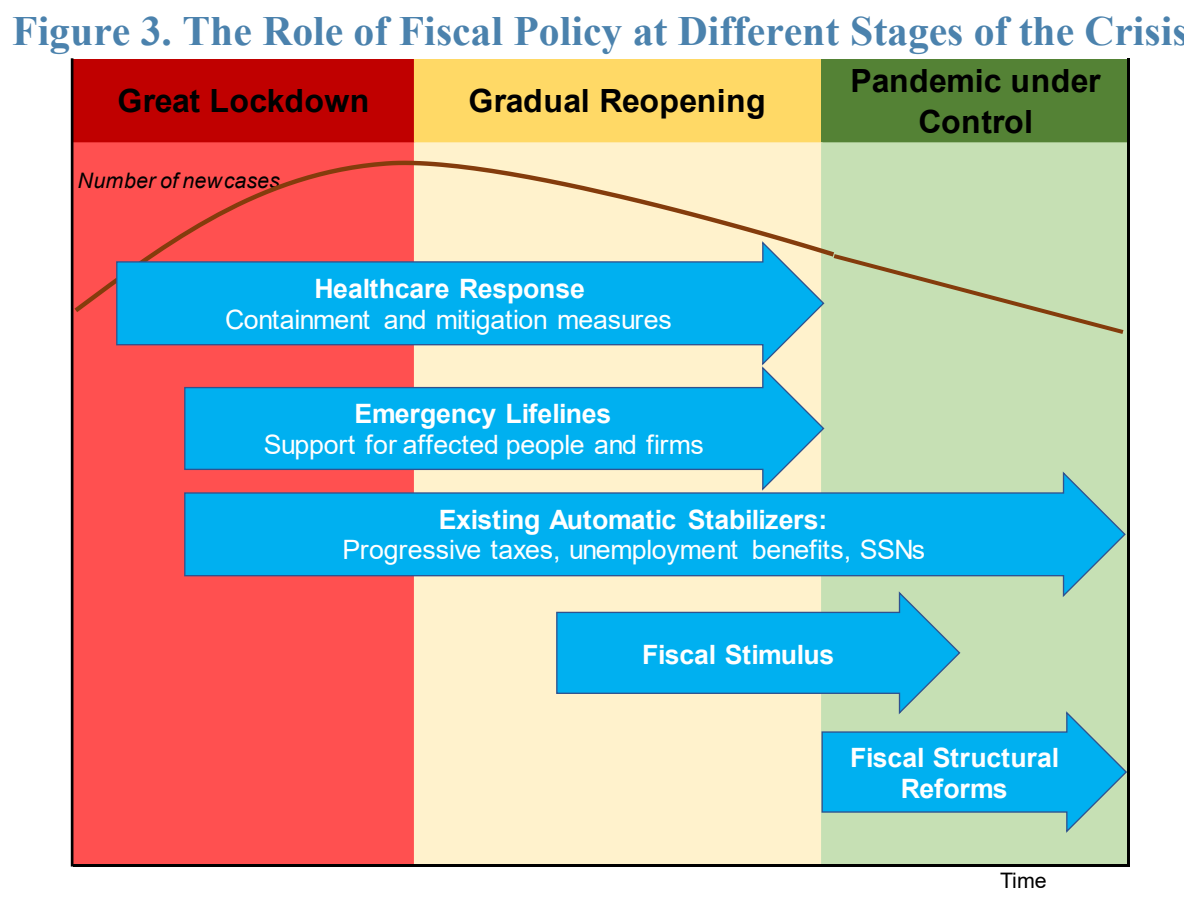

In this paper, we use the above three-phase schematic to elaborate the elements of a comprehensive fiscal policy response to Covid-19 for Mexico. We also simulate, using the IMF's Global Integrated Monetary and Fiscal (GIMF) model - see Kumhof and others (2010) and Anderson and others (2013) for modeling details - the macroeconomic effects of a proposed package that comprises larger fiscal support in the short-term and a growth-

\footnotetext{
${ }^{2}$ The difference between lifelines and fiscal stimulus is that lifelines are aimed at sustaining basic consumption levels by supporting households and helping viable firms temporarily (e.g., through expanded unemployment insurance, enhanced social safety nets, and liquidity support). Fiscal stimulus aims at boosting aggregate demand through broad-based measures (e.g., public consumption and investment, tax cuts).
} 
friendly and inclusive adjustment over the medium term. This is akin to a "fiscal twist". ${ }^{3}$ The model simulations suggest that a medium-term tax reform, alongside permanently higher capital spending and enhanced social safety nets, can generate sizable output gains, more redistribution, and a sustainably lower public debt ratio over the long term. Short-term output costs of the tax reform, if implemented credibly, are expected to be limited.

The rest of the paper is organized as follows. Section II discusses the desired near-term policy response to Covid-19 (for phases 1 and 2) and their cost estimates. Section III presents options for phase 3, including a medium-term tax reform. To enhance the political and public acceptability of the reform package, it also explores ways to enhance social safet nets. Section IV quantitatively simulates the macroeconomic effects of a growth-friendly mix of spending and revenue measures. Section V concludes.

\section{Box 1. Government's Fiscal Response to Covid-19 1}

In response to the Covid-19 pandemic and its economic fallout, the Mexican government has implemented a range of measures: 1) frontloading two bimesters payments of the oldage and disability pensions; 2) accelerating procurement processes and VAT refunds; 3) lending to firms and workers in both formal and informal sectors; 4) providing liquidity support through development banks.

Overall, the above-the-budget-line fiscal measures amount to 0.2 percent of GDP in health spending and 0.5 percent of GDP to support households and firms. Below-the-budget-line measures amount to 0.5 percent of GDP comprising loans to formal workers and recently laid-off employees as well as contingent liabilities.

Health spending. The government's measures aim to ensure that the Ministry of Health has sufficient financial resources and does not face red tape in procuring medical materials.

\section{Additional spending.}

- The Ministry of Economy is granting loans with optional repayments to 1 million smalland medium-sized enterprises (SMEs) that maintain employees on payroll, selfemployed and domestic workers (25 thousand pesos per loan), and another 1 million loans to family businesses previously registered in the Welfare Census (25 thousand pesos per loan).

- The government is providing subsidized unemployment insurance for 3 month to workers that hold a mortgage with the Housing Institute ( 7.3 billion pesos).

\footnotetext{
${ }^{3}$ Note that the global nature of the Covid-19 pandemic and the synchronicity of its macroeconomic effects might justify tolerance for higher debt levels temporarily. Chudik and others (2017) argue that there is no compelling evidence for a universally applicable threshold effect in the relationship between public debt and growth if one accounts for global interdependencies and common factors/shocks. However, they argue that a persistent accumulation of government debt is associated with lower growth in the long term. This suggests the need for medium-term fiscal adjustments once the pandemic is under control and the recovery is firmly in train.
} 
- Additional resources are allocated to social spending related to infrastructure, security, education, and other areas (50 billion pesos).

Accelerated spending.

- The government has frontloaded social pension payments for the elderly and disabled people by 4 months.

- Procurement processes and VAT refunds are to be accelerated.

Below-the-budget-line measures and contingent liabilities.

- The Government is implementing other measures, including housing credits for government workers with low-interest rates (ISSSTE' loans for a total amount of 35 billion pesos) and personal loans at a low rate (3 billion pesos).

- Development banks are to extend loans amounting 64.5 billion pesos, largely to SMEs.

Mexico: Key Fiscal Measures in Response to COVID-19

\begin{tabular}{|l|c|}
\hline \multicolumn{1}{|c|}{ Main measures } & Amount \\
& $\begin{array}{c}\text { (percent of 2020 } \\
\text { GDP) }\end{array}$ \\
\hline Total & $\mathbf{1 . 1}$ \\
Measures with budget impact & $\mathbf{0 . 7}$ \\
Support for households & 0.0 \\
of which & 0.0 \\
Unemployment subsidy for 3 months to workers that hold a mortgage with the Housing Institute (MXN 7.3bn) & 0.2 \\
Support for businesses & \\
of which & 0.1 \\
Loans with optional repayment to SMEs that maintain employees on payroll, self-employed, and domestic workers & 0.1 \\
Loans with optional repayment to family businesses previously registered in the Welfare Census & 0.2 \\
Supporting the health system & 0.2 \\
Others (additional social spending) & $\mathbf{0 . 5}$ \\
Below-the-line measures & 0.2 \\
Institute for Social Security and Services (ISSSTE) loans to state workers & 0.0 \\
Personal loans by the Institute of the National Fund for the Consumption of Workers (Fonacot) (MXN 3bn) & 0.3 \\
Loans by development banks, particularly to SMEs & \\
\hline
\end{tabular}

${ }^{1}$ Sources: Mexican authorities, staff estimates, IMF policy tracker, and IMF Fiscal Monitor: Database of Country Fiscal Policy Measures in Response to the Covid-19 Pandemic.

\section{Desired (Near-Term) Policy Response to Covid-19}

Whereas in normal economic downturns a key goal of fiscal policy is to stimulate demand, this crisis is like no other. In its early stages, the primary policy objectives are to: (1) save lives by containing the spread of the disease and treating those who are infected; and (2) protect livelihoods from the economic fallout of Covid-19. Correspondingly, the first policy priority is to fully accommodate spending on health care. The second priority is to adopt timely, temporary, and targeted fiscal actions to protect people and firms, including in hard-to-reach informal sectors. Such support is likely to provide the most effective cushion to 
output and essential consumption because it alleviates the drop in incomes for people with limited savings and reduces the likelihood of bankruptcies. In so doing, these actions would prevent a health crisis from generating large economic scarring effects.

The extent of fiscal actions and the choice of instruments during phase 1 of the crisis should be guided by some overarching principles, discussed in IMF (2020b). Lifelines should be cost-effective and transparently embedded in medium-term budget frameworks. Where possible, measures should build on existing programs to facilitate timely support to households and firms. Finally, financing constraints will determine the extent of emergency lifelines in phase 2 and a broad-based fiscal stimulus.

Guided by these overarching principles, it is advisable that Mexico's near-term fiscal support to combat the Covid-19 include:

\section{Healthcare}

- Universal free coverage for Covid-19 treatment, with no out-of-pocket expenditure, so that cost or access are not insurmountable barriers to combating Covid-19.

\section{Support to households}

- $\quad$ Assistance to households using existing social safety nets and administrative infrastructure (option 1): support to households could be provided by drawing on a recent social census covering about 20 million households (out of a total of 36 million) and Sistema de Información Social Integral (SISI), which collects data from social programs at all levels of government. Given the size of the shock, the generosity of existing programs and their coverage could be increased by including informal workers or those at risk of poverty, and temporarily easing eligibility requirements. The national voter ID database could be used to identify informal workers who do not have access to existing social safety net programs-i.e., adults not in the social census nor in SISI nor in the social security system nor in the tax administration records. Modes of delivery of assistance could include existing social safety nets, lower utility bills, mailing checks, setting up bank accounts for direct deposits (which also promotes financial deepening), or fintech instruments (e.g., mobile/online payments). ${ }^{4}$

- $\quad$ Assistance to households using enhanced social safety nets (option 2): an alternative but administratively more challenging approach is to create a single registry of beneficiaries by merging SISI with the social census. This would enable the government to better identify those in need, increase cost efficiency, and reduce errors of inclusion and exclusion, beneficiary overlaps, and program duplications (IMF 2019a).

- $\quad$ Other income and liquidity support measures for formal workers: These include (i) deferring employees' social security contributions; (ii) deferring tax payments; (iii) deferring and/or reducing mortgage, consumer loan, and utility bill payments;

\footnotetext{
${ }^{4}$ Complementary targeted subsidies for health, transportation, utilities etc. for certain sectors (e.g., trade, manufacturing, construction) or hard-hit regions are also possible options, although not essential if, as in Mexico, the social safety net has relatively wide coverage.
} 
(iv) providing government-funded sick and family leave; (v) relaxing requirements for accessing social security savings for formal workers - allowing them to draw a fraction of their future savings from their pension fund accounts on evidence of current hardship. Similarly, consideration could be given to allowing temporary access to insurance products, such as annuities. Careful calibration is essential to ensure any future costs are minimized, including to safeguard the intertemporal sustainability of pension and insurance funds.

\section{Support to firms}

Supporting viable ${ }^{5}$ firms, particularly small- and medium-sized enterprises (SMEs), could take two general forms: (i) liquidity support; and (ii) cost-reduction assistance.

- Options for liquidity support include tax and social security contribution deferrals; accelerated payments - expedited processing of VAT refunds; and clearing public sector arrears to all suppliers (if needed, prioritize those that use relatively low-skilled workers intensively) — and loans and/or credit guarantees. Regarding the latter, the government can (i) provide guarantees for rolling over of bank loans to ensure credit lines are maintained and essential liquidity remains available. Credit risk should be shared between the government and commercial banks to align incentives for loan provision only to viable firms; (ii) lend directly against collateral; (iii) lend to SMEs, with crosschecks of profitability based on previous tax payments; and (iv) ensure a mechanism is in place to monitor and record fiscal risks - e.g., to avoid abuse, a central body of guarantee organizations could check all loan agreements for compliance and guard against duplication of requests.

- Options for cost reduction include (i) lower social security contributions; (iii) forgivable loans; and (iii) wage subsidies. One possibility is to provide wage subsidies on conditions of retaining employees on the payroll to the extent possible while allowing for lower compensation, and of not using the subsidies for dividends, stock or debt buybacks, or CEO bonuses. Another option to support firms is to extend the provision of wage subsidies to informal workers (if any) as well should they be converted to formal workers. Pre-pandemic, about 12 million informal workers were employed in formal firms, or close to $1 / 5$ of the workforce. Since much of the benefits would take the shape of future income protection, that itself would sharply reduce present uncertainty for many families. Since the trade-off between current support and permanent costs into the future may be too much for some firms - an issue that needs to be investigated empirically to discern expected take-up - as an alternative, firms that formalize work arrangements could receive progressively greater levels of support. That is, the magnitude of additional support could be conditional on the fraction of informal workers that are formalized. Note that the provision of wages subsidies to formal workers should be exempt from this particular type of conditionally.

\footnotetext{
${ }^{5}$ Viability of a firm compares the present value (PV) of profits to the costs of recreating the firm from scratch. Solvency compares the PV of profits to the value of debt. Debt overhangs from crises can make a firm temporarily insolvent but still viable.
} 
However, for both the liquidity and cost-reduction options, some of the potential negative externalities should be borne in mind. Deferring social security contributions (SSC) could defray some burden on formal sector workers in the short-term, but this could also affect the viability of an already underfunded pension system if continued for an extended period.

Given the high number of infections in Mexico, the depth of the recession to date, and the relatively weak recovery anticipated by many analysts, the government could consider keeping emergency lifelines in place for longer and durably strengthening social safety nets over time. To facilitate the recovery, the authorities could plan to enact, for example, temporary cost-reduction incentives to encourage private investment, as well as to accelerate high-return public investment projects, repair, and maintenance activities. ${ }^{6}$ As uncertainty about medium-term prospects is resolved, they could also facilitate structural transformation - facilitating the reallocation of resources toward activities that are likely to see growing demand once the pandemic is under control - through hiring subsidies (conditional on formalization) and spending on worker re-training.

\section{A. How much does the near-term policy response cost?}

The near-term fiscal response to Covid-19 are grouped into the following categories and costed: (i) additional health expenditure amounting to 0.6-1.5 percent of GDP; (ii) support to households of about 1.2 percent of GDP; (iii) support to firms (including wage subsidies of 0.4 percent of GDP); and (iv) increased investment of 0.4 percent of GDP. Overall, the estimated cost of these emergency lifelines would be $2.5-3.5$ percent of the 2020 GDP. This number excludes support in the form of loans, equity injections, and credit guarantees.

\footnotetext{
${ }^{6}$ General tax rate cuts and holidays should be avoided.
} 
Table 1. Estimated Cost of Key Measures

\begin{tabular}{|c|c|c|}
\hline Measures & Assumptions & $\begin{array}{l}\text { Estimated cost } \\
\text { (percent of GDP) }\end{array}$ \\
\hline Total & & $2.6-3.5$ \\
\hline Healthcare & & $0.6-1.5$ \\
\hline Accommodate additional health spending & $\begin{array}{l}\text { Based on Dudine et. al. (2020) that combines a simple } \\
\text { Susceptible-Infectious-Recovered (SIR) epidemiological model } \\
\text { and assumptions about pre-pandemic spare capacity, cost of } \\
\text { providing care and of increasing capacity in the health sector }\end{array}$ & $0.6-1.5$ \\
\hline $\begin{array}{l}\text { Support to households by... } \\
\text {...expanding existing social safety nets }\end{array}$ & & 1.2 \\
\hline To readily eligible beneficiaries & $\begin{array}{l}\text { Offer benefits to those who were eligible but did not receive any } \\
\text { social assistance in } 2019 \\
\text { 3-month support of } 2036 \text { pesos per month (average of poverty }\end{array}$ & 0.6 \\
\hline To people at risk of poverty & $\begin{array}{l}\text { lines) for people at risk of extreme poverty, as estimated by } \\
\text { CONEVAL }\end{array}$ & 0.3 \\
\hline To informal workers in hard-hit sectors & $\begin{array}{l}\text { 3-month support of } 2036 \text { pesos per month to informal workers } \\
\text { in construction, trade, and services sectors using sector-specific } \\
\text { lockdown assumptions }\end{array}$ & 0.3 \\
\hline Support to firms & & 0.4 \\
\hline Wage subsidies & $\begin{array}{l}\text { 6-month support of } 2036 \text { pesos per month to IMSS-insured } \\
\text { workers of formal firms in construction, trade, and services } \\
\text { sectors using sector-specific lockdown assumptions }\end{array}$ & 0.4 \\
\hline Boost public investment & $\begin{array}{l}\text { Increase good-quality public investment to support a fraction of } \\
\text { private investment lost because of COVID-19 }\end{array}$ & 0.4 \\
\hline
\end{tabular}

\section{Cost estimates of healthcare}

Health spending should be increased to mitigate the spread of Covid-19 and treat those that are infected (Dudine and others 2020). The estimated cost would be contingent upon a host of factors: the pre-Covid-19 capacity in the health system, the cost (both fixed and variable) required to expand the existing capacity if needed, and the pathway of the Covid19 pandemic. If new cases and hospital occupancy rates decline durably, health resources would need to focus on the next phase of the pandemic, such as preparing for a large-scale vaccine rollout. The cost of prevention and treatment would depend on countryspecific factors such as demography, geography, preparedness of the existing health infrastructure, effectiveness of non-pharmaceutical mitigation measures, specific factor costs (e.g., compensation of health professionals), and the stage of the outbreak (IMF 2020c). 
The estimation of health spending is an inherently difficult task in the current environment and is fraught with uncertainty - related to the trajectory of cases and measurement accuracy, the availability of granular data on health capacity, the impact of containment measures, economic reopening plans/status, and vaccine development and rollouts. It is even more difficult to incorporate the quality of healthcare when estimating the cost; this paper does not explicitly account for this factor. With

Figure 5. Public Health Expenditure (Share of GDP)

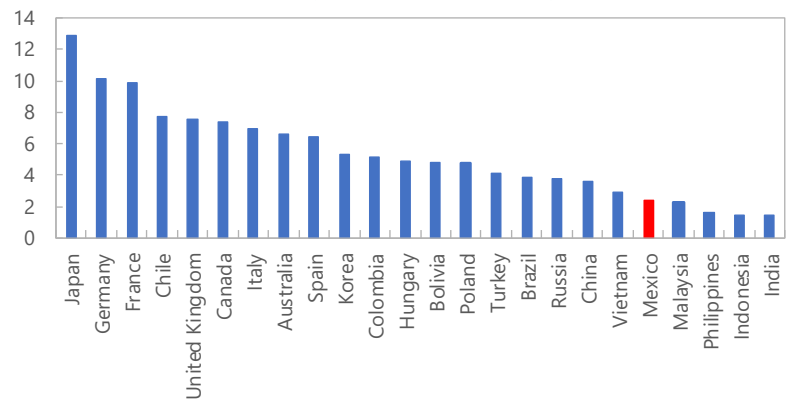

Most recent year available. Source: IMF (2019) for Mexico; WDI (via IMF EAT Database) for all other countries. these caveats in mind, we consider that health spending could be increased by $0.6-1.5$ percent of GDP in Mexico, based on the following:

(1) Benchmarking: The average health spending on Covid-19 in G20 countries and Mexico's regional peers is 0.6 percent of GDP, higher than Mexico's current Covid-related health spending of 0.2 percent. Mexico is likely to require even more resources than its peers, given that its healthcare system is fragmented, service delivery is unequal (spending remains concentrated on richest states), and administration costs are high (see IMF 2019 for details). Moreover, health expenditure as a share of GDP and pre-existing number of beds and physicians are lower than many other countries (Figures 5 and 6). In addition, co-morbidity factors are high because of elevated incidence of obesity and diabetes, among others.

Figure 6. Pre-Covid-19 Health Capacity
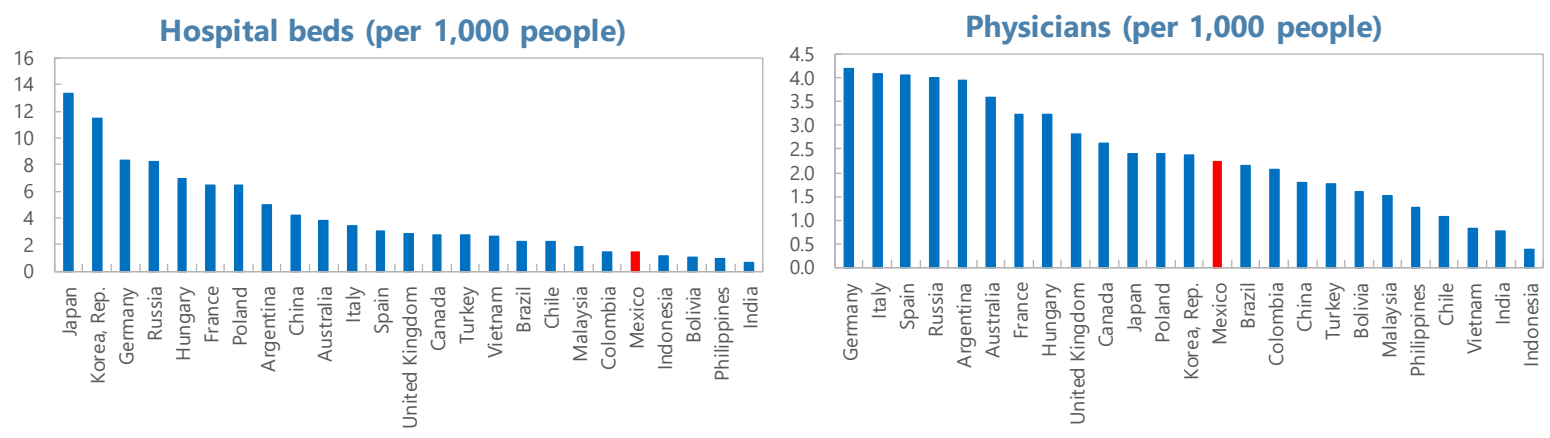

Most recent year available. Source: WDI.

(2) Model estimates: We follow Dudine and others (2020) in estimating the size of additional health spending needed to treat Covid-19 patients based on a simple Susceptible-InfectiousRecovered (SIR) epidemiological model that projects country-specific number of persons requiring hospitalization. This number is combined with assumptions about capacity constraints in the health sector, information about average healthcare cost, and additional 
funds needed to expand health capacity to compute the overall additional health spending needed for Mexico. The model captures some non-linear effects: (i) the pressure on the health system depends more on the distribution of Covid-19 patients than the total number of cases; (ii) the additional spending needs depend on capacity constraints (spare beds, ventilators, and availability of doctors/nurses) and technical constraints to health system expansion; and, (iii) the role of other policies in slowing the spread of the virus.

The estimated healthcare costs are based on two scenarios, detailed in Table 2. These parameter values can be plugged into the template of Dudine and others (2020) to arrive at the healthcare cost estimates for Mexico. While the second scenario uses the paper's default parameters, the first scenario modifies a few of these values, including reproduction rates ( $\rho 0$ and $\rho 1$ ) - informed by the studies of IMF (2020d) and Parr (2020). The reproduction rates for the first scenario is comparable to the upper bound $\left(97.5^{\text {th }}\right.$ percentile) of IMF (2020d)'s estimates as officially reported fatalities could be underestimated by around three times (Zavala and Despeghel 2020). The first scenario assumptions result in new cases of 16 percent of population by the first year, while the equivalent new cases in the second scenario is 53 percent of population. When estimating the healthcare costs, the first scenario assumes a capacity increase of 25 percent maximum (parameter cap in Table 2).

Based on these assumptions, the estimated cost could range between 0.7-1.7 percent of GDP for total health cost and 0.6-1.5 percent of GDP for public health cost (assuming different public versus private split, but more than 85 percent in both cases presented). The wide range of estimates reflects the considerable uncertainties associated with this exercise. In particular, the cost is very sensitive to assumptions such as how much capacity can be increased and the reproduction number for Covid-19 (average number of new infections per infected) - factors that cannot be accurately pinned down ex ante.

Table 2. Epidemiological Parameters

\begin{tabular}{|c|c|c|c|}
\hline Parameter & Scenario 1 & Scenario 2 & Comment \\
\hline $\mathbf{K}$ & 0.4 & 0.4 & $\begin{array}{l}\text { Share of infected people that is not infectious after } 1 \text { week, either because of recovery or } \\
\text { death. }\end{array}$ \\
\hline$\rho 0$ & 2.4 & 2.3 & $\begin{array}{l}\text { Average number of new infections per infected person over the duration of infection, when } \\
\text { no control measures are taken }\end{array}$ \\
\hline$\rho 1$ & 1.3 & 1.5 & $\begin{array}{l}\text { Average number of new infections per infected person over the duration of infection, when } \\
\text { control measures (quarantine, lockdowns, etc.) are taken }\end{array}$ \\
\hline $\mathbf{W}$ & 8 & 10 & Number of weeks it will take to switch to $\rho 1$ since the beginning of the outbreak \\
\hline $\mathbf{S}$ & 0 & 0 & Share of population that will not get infected (in other words, immune population) \\
\hline$\alpha$ & 1 & 1 & Share of those hospitalized who cannot infect others \\
\hline Scale up $z$ & 1.1 & 1.1 & Multiply estimate of country specific $z$ \\
\hline $\begin{array}{l}\text { Scale up } \\
\text { mortality }\end{array}$ & 1.1 & 1.1 & Multiply estimate of country specific $\delta^{\mathrm{H}}$ \\
\hline$\Delta \delta^{\mathrm{RNH}}$ & 0.03 & 0.03 & Increase in death rate for people requiring but not obtaining hospitalization \\
\hline av & 0.05 & 0.05 & Share of existing beds at time zero, available to Covid- 19 patients \\
\hline nb & 0.1 & 0.1 & $\begin{array}{l}\text { Share of patients requiring but not obtaining hospitalization that can be hospitalized next } \\
\text { period }\end{array}$ \\
\hline cap & 1.25 & 1.5 & Multiple of beds available at time zero above which the health system cannot go \\
\hline $\mathbf{c m}$ & US\$5,000 & US\$5,000 & Cost of medicine and other material per week, per hospitalized patient \\
\hline cnb & US\$25,000 & US\$25,000 & Cost of a new bed and equipment \\
\hline Fc_100 & US\$1,000,000 & US\$ $1,000,000$ & Fixed costs associated to expanding capacity by 100 new beds \\
\hline
\end{tabular}




\section{Cost estimates of support to households}

Mexico currently spends about 2.2 percent of GDP on social safety nets (or social assistance). There are around 8,000 social protection programs at the federal, state, and municipal levels. ${ }^{7}$ These programs cover 22.9 million Mexicans in the year 2020 (equivalent to 16 million households or 44.5 percent of total). Those in need are largely identified from the social census and SISI. The one-year cost of increased households assistance is estimated at 1.2 percent of GDP.
Figure 7. Social Assistance Spending (Share of GDP)

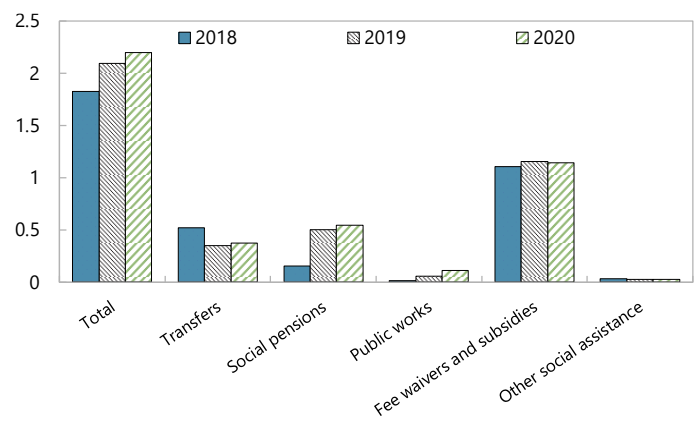

Source: SHCP

\section{Expanding the existing social safety nets}

Estimate 1: Increase the coverage of social safety nets to readily eligible individuals. These are individuals who have been deemed eligible but have not received any benefits yet. Using different assumptions about the extent of coverage of such beneficiaries, CONEVAL, which is Mexico's agency for measuring poverty and evaluating social development policies, estimated in May 2020, the additional cost of expanding existing programs to be 0.2-0.6 percent of GDP, based on two scenarios:

- The first scenario assumes full coverage of 8,873,924 beneficiaries who were eligible but did not receive any assistance in 2019. The additional cost would amount to MXN 137 billion or 0.6 percent of GDP.

- The second scenario assumes a 30 percent increase in coverage $(2,815,133$ beneficiaries) - the increase in the percentage of the population in poverty between 2008 and 2010 - yielding an estimated cost of around 0.2 percent of GDP.

Estimate 2: Increasing the coverage of social safety nets by including those at risk of poverty. Based on various assumptions about the extent of income loss from Covid-19, CONEVAL estimates that the total number of people in extreme poverty might increase between 6.1 and 10.7 million, while the UN/ECLAC projects a substantial increase of 14-21 million (assuming the population living in extreme poverty increases from 11.1 percent in 2019 to 14.9-17.1 percent in 2020). The Centre for Educational and Social Studies estimates that 11.5 million people could move out of the middle class into relative poverty. The economic shock accompanying the pandemic therefore significantly expands those in relative and extreme poverty.

\footnotetext{
7 The IMF defines social protection spending to comprise social insurance and social assistance programs. Social insurance aims at protecting households from shocks that can adversely impact their incomes and welfare and is typically financed by contributions or payroll taxes. This includes the pension system and health care for the population in general. Social assistance aims at protecting households in poverty and is financed by general government revenue. This relates specifically to poverty alleviation and includes direct and indirect transfers to poor households as well as social pensions to the elderly to tackle old age poverty. The terms social assistance and social safety net are used interchangeably in this paper.
} 
Using the CONEVAL estimate, the cost of providing temporary support to 6.1-10.7 million people is $0.2-0.3$ percent of GDP assuming that: each individual is provided an income support of MXN 2036.12 per month (average of urban/rural poverty and extreme poverty lines, as computed by CONEVAL for July 2020) for 3 months. The estimated cost would be contingent on the amount of monthly support, its duration, and the underlying assumption on the duration of the shock. With potentially substantially higher durations of non-employment and under-employment, the amount of support would be notably higher. For example, using the same underlying assumptions for computation, 6 months of support would amount to 0.30.6 percent of GDP, while 12 months of support would amount to 0.7-1.2 percent of GDP.

Estimate 3: Increase the coverage of social safety nets to informal workers. Informality in Mexico's labor market takes many forms, including those at non-agricultural informal firms, self-employed agricultural firms, unpaid workers, non-salaried workers ${ }^{8}$, and workers without access to social security health services (Alvarez and Ruane 2019). None of the workers under this definition has access to Mexican Social Security Institute (IMSS). It must be noted that informal workers could be employed in both formal and informal firms ${ }^{9}$. There are about 56 million workers, of which about 23.5 million are formal using the shares from Alvarez and Ruane 2019 (around 21 million insured by the Mexican Social Security Institute, IMSS). Given widespread informality, it is necessary to have different programs to target different forms of informal workers and formal employees.

Covering informal workers of hard-hit sectors depends crucially on the phase of the crisis. In phase 1, manufacturing, construction, trade, and services were particularly hard hit. In phase 2 , auto manufacturing and construction sectors were deemed essential, and a recovery in production and employment have been underway. However, the loss in employment in construction was particularly sharp, and is well below pre-pandemic levels. Keeping these considerations into account, the analysis assumes support for informal workers of construction, trade, and services sectors. It must be noted that we use high-level assumptions to show illustrative calculations based on possible strains in certain sectors. These need to be complemented with analysis using more granular data for policy implementation.

Calculation of the estimated cost:

- The number of informal workers is approximated using data on IMSS-insured workers across these sectors. We assume that 58 percent of total workers across each sector are informal (Alvarez and Ruane 2019). The total number of formal workers in construction, trade, and services in 2019 was 10.5 million. If 58 percent of total employment consists

\footnotetext{
8 "Salaried workers are hired by entrepreneurs in relation of subordination and receive wages in return of their efforts (fixed payments per unit of time)......Non-salaried workers can be self-employed or associated with firms but not in a subordinated relation, receiving remuneration in various forms (per unit produced or sold, per task accomplished, profit-sharing, and the like), but not wages." Levy (2018, pp.14).

${ }^{9}$ According to Alvarez and Ruane (2019), informal firms include subsistence agriculture, domestic work, and firms classified as informal by the Mexican Institute of Statistics and Geography (INEGI) based on reported name, family ownership, and accounting practices. All other firms are formal.
} 
of informal workers, this would imply there are 14.6 million informal workers. ${ }^{10} \mathrm{~A}$ sector-specific lockdown parameter of around 0.7 is assumed, that is, around 70 percent of workers in these industries might need help. This implies that around 10 million informal workers from these sectors would require support.

- 3-month income support of MXN 2036.12 per month (average of urban/rural poverty and extreme poverty lines, as computed by CONEVAL for July 2020) is provided to these 10 million informal workers. This would amount to MXN 61.6 billion, which is equivalent to 0.3 percent of GDP.

The estimated cost is sensitive to the assumptions of the amount and duration of support and lockdowns. To illustrate this caveat, Figure 8 plots the estimated cost of supporting the informal workers for these targeted sectors, varying the lockdown assumptions and the amount of monthly support. The estimated cost ranges from 0.1-0.5 percent of GDP. The cost would also depend on the duraton of the support. The calcuation assumes 3 months of support. However, if the

Figure 8. Cash Transfers to Informal Workers (Share of GDP)

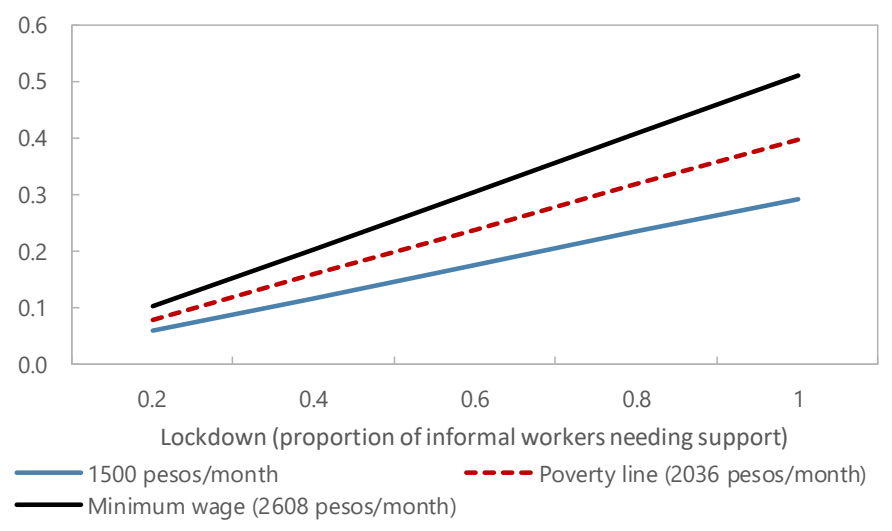
effects of the pandemic are prolonged - both in terms of the duration of the health crisis and the subsequent pace of recovery - the support may need to be extended for longer.

\section{Cost estimates of support to firms}

Estimate \#1. Wage subsidies to formal workers of hard-hit sectors (construction, trade, and services), assuming sector-specific lockdown assumptions and six months of 2036 pesos payments, would require support of 0.4 percent of GDP. The underlying calculation follows the method explained above for informal workers with the same caveats applied. In particular, the choice of the sectors has been determined using the same considerations related to developments in phases 1 and 2, as described previously. The policy of subsidized wages should be flexible and adjusted over time to mitigate the unintended adverse consequences for labor market reallocation responses to the Covid-19 shock (Barrero, Bloom and Davis, 2020).

Estimate \#2: The banking sector credit to SMEs amounts to 11 percent of GDP. Assuming an average maturity of 3 years, about 1 percent of GDP of credit falls due each quarter. The rollover risk could be mitigated through development banks directly extending loans (against

\footnotetext{
10 This is an approximation since sectoral distributions do not necessarily match the aggregate distribution. Using this approach for all sectors, total employment across all sectors is 49 million. Actual data suggests employment of 56 million people. As such, this calculation could be regarded as a lower bound.
} 
collateral) for about 1-2 percent of GDP. Alternatively, development banks could share (or backstop) the credit risk with commercial banks to facilitate rollover.

\section{Cost estimate of accelerated/additional investment}

The authorities have already allocated 0.2 percent of GDP to social spending including public works, security and education in response to Covid-19. This could be increased to 0.4 percent of GDP, including investing in maintenance and restarting good projects that were delayed, to recuperate a fraction of the private investment lost. The $2020 \mathrm{WEO}$ projection for private fixed investment has decreased from 17.7 percent of GDP (pre-Covid-19) to 16.5 percent of GDP in July 2020 (WEO) version, a decline of 1.2 percentage points. Assuming that a quarter of the lost investment could be replaced by public investment, we arrive at a cost estimate of around 0.4 percent of GDP.

\section{MEDIUM -TERM FisCAL REFORMS}

Considering that social spending is set to increase rapidly over time (as a result of the Covid19 pandemic and, even before that, as a key priority for the current government) and other expenditure pressures are emerging in Mexico, raising revenues from their current exceptionally low levels will be indispensable to finance social spending sustainably and create space for a more forceful near-term response to Covid-19 and its economic fallout. There is also a need to increase public investment permanently and enhance social safety nets to increase the political/public acceptability of the needed tax reforms.

\section{A. Increase Tax Capacity}

Despite impressive recent gains, Mexico's tax revenues are the lowest in OECD and lag regional peers. In 2014, the government passed a tax reform that set limits to deductions and exemptions, introduced new tax brackets, created taxes on dividends and gains, and introduced an excise tax on sodas, junk food, pesticides and carbon-producing products. As a result, federal tax revenue increased by almost 3 percentage points of GDP, which helped offset a large decline in oil revenues. However, at 13.2 percent of GDP in 2019, non-oil tax revenues remain well below the OECD and Latin America averages of 26 and 19 percent of GDP, respectively. Importantly, revenue from VAT has stagnated and remains much below that of other countries. This section proposes a reform that would deliver at least 3 percent of GDP in additional tax revenues. It would center on policy and administration actions that could improve VAT performance, rationalize inefficient and regressive income tax expenditures, and widen the top personal

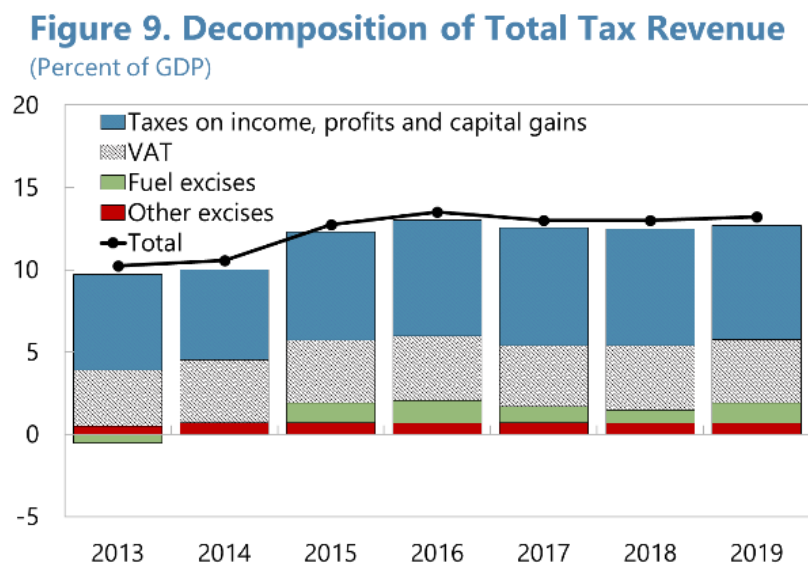
income tax bracket. 


\section{Significant Scope to Improve VAT Performance}

Value-added tax (VAT) collection in Mexico is low compared to OECD countries and Latin America. In 2019, net of refunds, it reached only 3.9 percent of GDP (significantly less than the OECD average of 7.0 percent and the Latin America average of 7.3 percent). The Cefficiency of VAT at 29 percent - the ratio of actual VAT collections (ABFD area in Figure 10) to the theoretical revenues under a perfectly enforced tax levied at the standard rate on all final consumption without any exemptions (ACHE area in Figure 10) - is one of the lowest among OECD countries and Latin America (that has an average C-efficiency of 50 percent). ${ }^{11}$

The low level of VAT C-efficiency in Mexico can be explained by a narrow base (owing to tax expenditures and informality) and by high non-compliance. In general, there are three main factors that can explain a low level of tax collection in a country: (i) low rates; (ii) a narrow base; and/or (iii) non-compliance (IMF 2018). At 16 percent, the standard VAT rate in Mexico is not significantly lower than the averages of OECD countries and Latin America. The base of the VAT in Mexico is reduced mainly for two reasons: (a) tax expenditures on final products (such as exemptions of education and housing as well as zero ratings of domestic transactions). These amounted to 1.43 percent of GDP in $2019(0.26+1.17$ in Table 3 ); and (b) exclusions from the object of the tax (owing to informality, for example). At the same time, the VAT compliance gap is relatively high: estimated by IMF (2018) at 45.8 percent of potential revenue in 2016 (or 2.41 percent of GDP). Non-compliance and tax expenditures are related: exemptions and zero rating of domestic transactions, in addition to eroding the tax base, make control difficult and thus facilitate evasion.

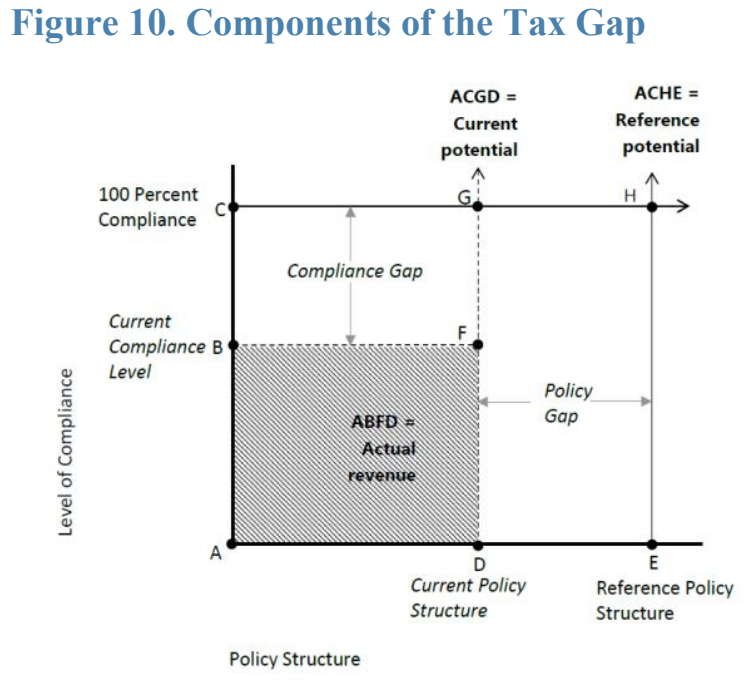

Source: IMF (2017).

\begin{tabular}{lccc} 
Table 3. Tax Expenditures (Percent of GDP) \\
\hline & $\mathbf{2 0 1 8}$ & $\mathbf{2 0 1 9}$ & $\mathbf{2 0 2 0}$ \\
\hline VAT & $\mathbf{1 . 3 6 1}$ & $\mathbf{1 . 4 3 2}$ & $\mathbf{1 . 4 3 2}$ \\
Zero ratings & 1.106 & 1.167 & 1.167 \\
Exemptions & 0.255 & 0.265 & 0.265 \\
PIT & $\mathbf{0 . 9 6 7}$ & $\mathbf{0 . 9 5 2}$ & $\mathbf{0 . 8 9 6}$ \\
Deductions & 0.118 & 0.102 & 0.102 \\
Exemptions & 0.718 & 0.733 & 0.683 \\
Special or sectoral schemes & 0.128 & 0.116 & 0.110 \\
Deferrals & 0.004 & 0.001 & 0.001 \\
CIT & $\mathbf{0 . 5 1 8}$ & $\mathbf{0 . 4 9 5}$ & $\mathbf{0 . 4 9 5}$ \\
Deductions & 0.089 & 0.099 & 0.099 \\
Exemptions & 0.051 & 0.047 & 0.047 \\
Special or sectoral schemes & 0.048 & 0.047 & 0.047 \\
Deferrals & 0.104 & 0.082 & 0.082 \\
Administrative facilities & 0.022 & 0.022 & 0.022 \\
Employment allowances & 0.205 & 0.198 & 0.198 \\
Special Taxes & $\mathbf{0 . 2 5 5}$ & $\mathbf{0 . 2 6 5}$ & $\mathbf{0 . 2 6 5}$ \\
Exemptions & 0.255 & 0.265 & 0.265 \\
Fiscal Incentives & $\mathbf{0 . 8 0 9}$ & $\mathbf{0 . 8 4 3}$ & $\mathbf{0 . 4 9 9}$ \\
\hline
\end{tabular}

Source: SHCP.

\footnotetext{
${ }^{11}$ Observed C-efficiency should equal the inverse of the total VAT gap, i.e., (1 - tax gap) or (1 - policy gap) x (1 - compliance gap). The compliance gap is the difference between the potential VAT that could have been collected given the current policy framework and actual accrued VAT collections (BCGF in Figure 1). The policy gap is the difference between the overall tax gap and the compliance gap.
} 


\section{Policy recommendations:}

- Reduce policy gap. The "first-best" option to broaden the VAT base in Mexico includes eliminating all domestic zero-rate items, except for a few key foodstuffs, and reducing exemptions. These actions alone could boost revenues by more than 1 percent of GDP. They should be accompanied by spending measures to address distributional concerns (through strengthened social safety nets) as, in general, VAT exemptions and reduced rates are a poor tool for protecting lower-income households or improving income distribution, given weak targeting. While lower-income households spend a greater share of their income on consumption,

Figure 11. Benefits from Zero-Rated VAT on Food, by Income Decile (Percent)

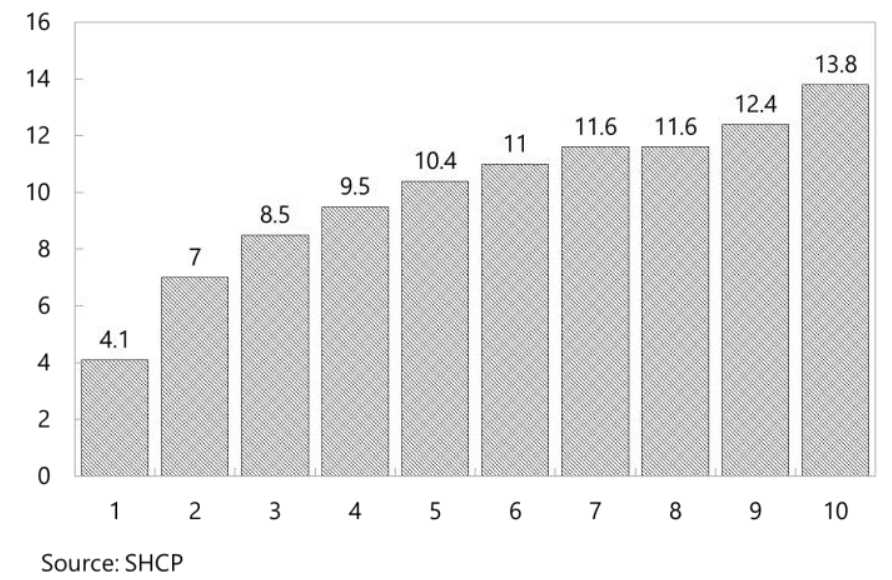
higher-income households consume absolutely more. This is shown in tax expense estimates of the Mexican Finance Ministry (SHCP) for the year 2019, where the highest income decile received 13.8 percent of the benefits from zero rate VAT on food, while the lowest income decile received 4.1 percent of the benefits. Additional spending through social safety net programs is a better way to improve equity. Among OECD countries, Denmark, New Zealand, Chile and Estonia have opted for a broad-based, simpler and more economically efficient VAT and redistribute part of the additional revenue obtained through well-targeted social safety net programs.

- Reduce compliance gap. Mexico already has an adequate toolkit to combat tax evasion. Staff recommends adopting a comprehensive strategy to tackle non-compliance in line with the 2018 IMF technical assistance, which could result in revenue gains of 1 percent of GDP. This includes improving the tax agency's (SAT) fragmented organizational structure, simplifying the small taxpayer regime, and moving toward a high-coverage audit process for VAT returns. The recent abolition of the right to offset excess tax credits against other taxes should reduce fraud once the backlog of grandfathered claims clears. Strengthening sanctions against tax fraud would also be welcome.

Overall, fundamental VAT reforms to reduce both policy and compliance gaps over the medium term could increase revenues by at least 2 percent of GDP (IMF 2018). If Mexico were to raise the C-efficiency of VAT to the average of Latin America (50 percent), revenue would increase by more than 2 percent of GDP. Such a revenue gain is much-needed, given the expected marked decline in oil revenues over time and increased desire/need for additional social protection and public investment. However, it has repeatedly proved politically difficult since early 2000s. Moreover, as revenue gains from strengthened compliance will take time to materialize, fiscal planning should be prudent and not ex ante count on large gains (as assumes in model simulations). Accompanying measures to increase acceptability by strengthening social safety nets could cost about 0.5 percent of GDP. 
It should be noted that if "second-best" alternatives are pursued owing to political economy constraints, it would be advisable to seek not only a partial improvement over the status quo but also a path that ultimately approaches the "first-best." For example, VAT exempting all domestic zero-rated items would decrease the complexity of the tax structure and reduce the number of VAT refunds, bringing some relief to the tax administration. However, the tradeoff would be limited overall revenue gains, with disproportionate leakage of benefits to the better off and non-use of better means to support to the poor.

\section{Some Scope to Increase PIT Revenues}

The personal income tax (PIT) system is performing very weakly in international comparison. PIT revenues in Mexico are some 5 percent of GDP less than the OECD average, reflecting informality and inequality with a large low-wage sector paying very little tax, given the progressivity of PIT. While there is limited scope for increasing PIT revenue through rate increases, the tax base can be expanded. Exclusions from the PIT net are prevalent such as income on personal business

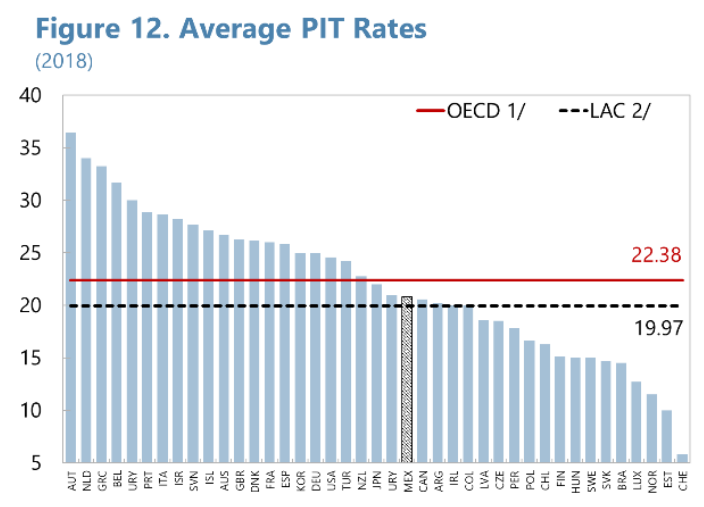
activities and independent services. Apart from withholdings on wages and salaries, personal income tax revenues are negligible. Tax expenditures for PIT are also sizable: close to 1 percent of GDP in 2019. The authorities consider that at least 0.5 percent of GDP of these tax expenditures are inefficient or regressive and could be rationalized (IMF 2019c). Moreover, the threshold for the top PIT bracket (which has been increased by five percentage points as part of the 2014 tax reform) could be lowered to widen the base, as it is a significant outlier compared to peers. Overall, the potential revenue gains from PIT reforms are about $0.5-1$ percent of GDP.

Figure 13. Progressivity of PIT (Percent and USD)

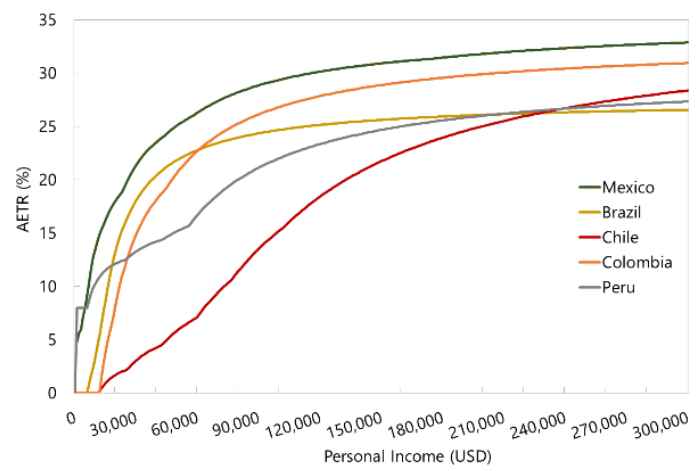

Sources: IMF staff estimates using IBFD data. Note: Lines show the Average Effective Tax Rate (AETR) by Personal Income Level.
Figure 14. Bottom and Top PIT Brackets (Percent of per-capita GDP)

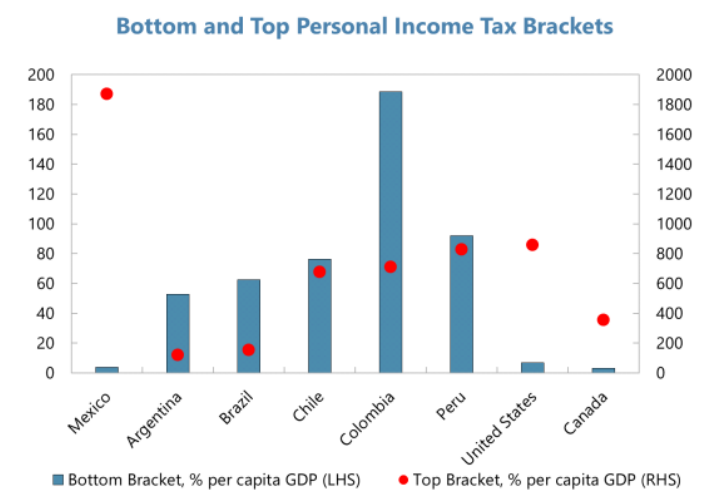

Source: FAD Revenue Analysis Tool. 


\section{Limited Scope to Increase CIT Revenue}

Mexico's corporate income tax (CIT) system features a relatively high tax rate and revenue, and a fairly typical base. The CIT rate is a flat 30 percent, which is above the U.S. federal rate of 21 percent and the average of OECD countries. CIT revenue makes up a quarter of the low overall tax take and, at 3.6 percent of GDP, compares favorably with the OECD average of 2.8 percent. Such a strong reliance on CIT revenue as well as rate differentials expose Mexico to potential revenue losses associated with profit-shifting and, over the medium term, relocation of production if rates were to be increased (which however is unlikely). ${ }^{12}$ The tax base is also fairly typical and tax expenditures under the CIT are limited $(0.5$ percent of GDP) and likely overstated. This is because deferred taxes, a part of deductions and administrative facilities reflecting genuine business costs, and employment subsidies (partly addressing the unusual feature of the PIT system, where income is taxed from the first peso) are included in tax expenditures. Overall, considering that the productivity of CIT is at the average of international peers and above that of several advanced economies, there seems to be little scope to increase CIT revenue through base broadening measures. The revenue agency (SAT) has been diligently pursuing collections against several corporations in recent months, including in a number of high-profile settlements. The above-mentioned assessment of CIT taxes, however, notes that significant further scope for revenue collection in this area is not likely to be as much as similar efforts, alongside tax policy reform, in the areas of VAT and PIT.

Figure 15. Corporate Income Tax Rates and Productivity
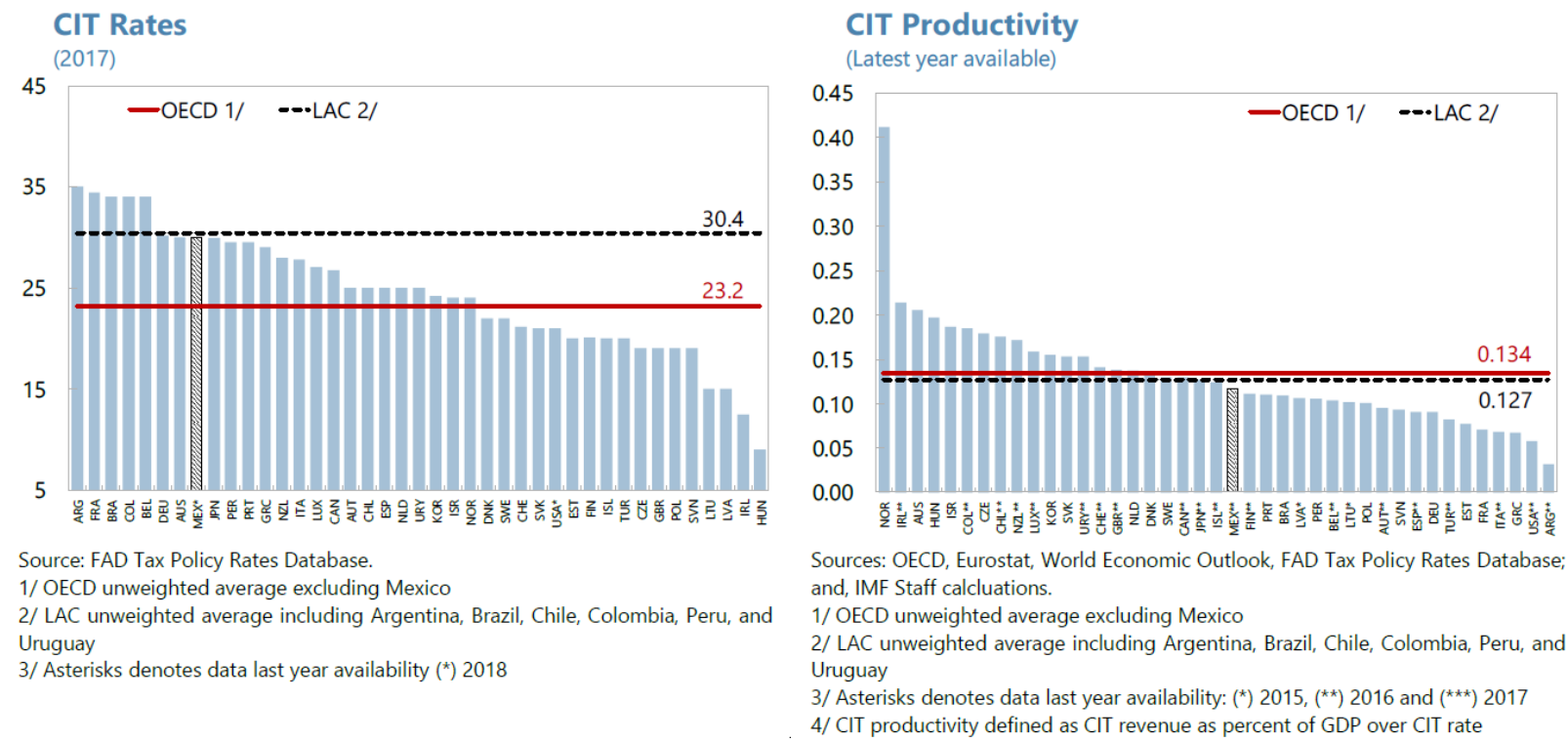

${ }^{12}$ An important feature of the Mexican tax system is the treatment of certain export-oriented operations, known as the maquila sector, which are taxed under safe harbor or Advance Pricing Agreement rules, implying that their CIT base is estimated as a percentage of their assets or costs. 


\section{Other taxes}

Gasoline excise tax. The current formula guarantees cumulative retail fuel price growth below CPI inflation since November 30, 2018. This policy disproportionately benefits the rich and should be revoked, which could provide some 1/4 percent of GDP in additional revenues. Moreover, in a low oil price environment, there is scope to increase gasoline excises.

Subnational taxes. Over the medium term, there is much potential to increase revenue from strengthening property taxation-which is currently 1.5 percent of GDP less than the average of Latin American countries. A reform could be facilitated by creating an agency at the federal level to update the cadaster, as well as by policy coordination at the subnational level to avoid fragmentation. Closing the gap in collections visà-vis peers could take time but, at a minimum, the aim could be to collect at least $3 / 4$ percent of GDP. This could be complemented with a redesigned vehicle registration tax by simplification and stricter enforcement, hence enabling a reduction in

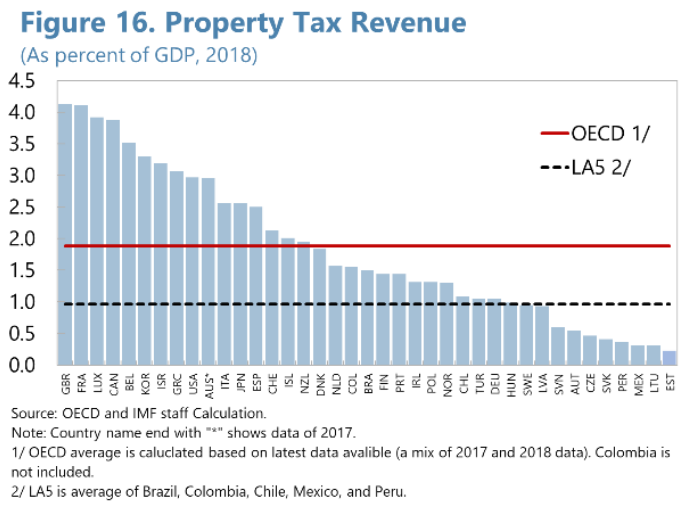
transfers to states and municipalities.

\section{B. Raise Public Investment}

In the medium term, the proposed package includes an increase in public investment of 1.5 percent of GDP, out of which a third is allocated to healthcare.

Public investment. High-return public investment can act as a bridge to sustainable, resilient, and inclusive economic growth, including by lifting productivity, creating jobs, and spurring private sector investment (IMF 2020b). In the case of Mexico, IMF (2019a) shows that there is a crucial role for basic infrastructure investment (in particular, road infrastructure) in boosting firm productivity, including for the large number of micro firms. In this regard, the trend decline in public investment-to-GDP ratios in Mexico is concerning. Investment spending, as a share of GDP, has declined from 4 percent of GDP over

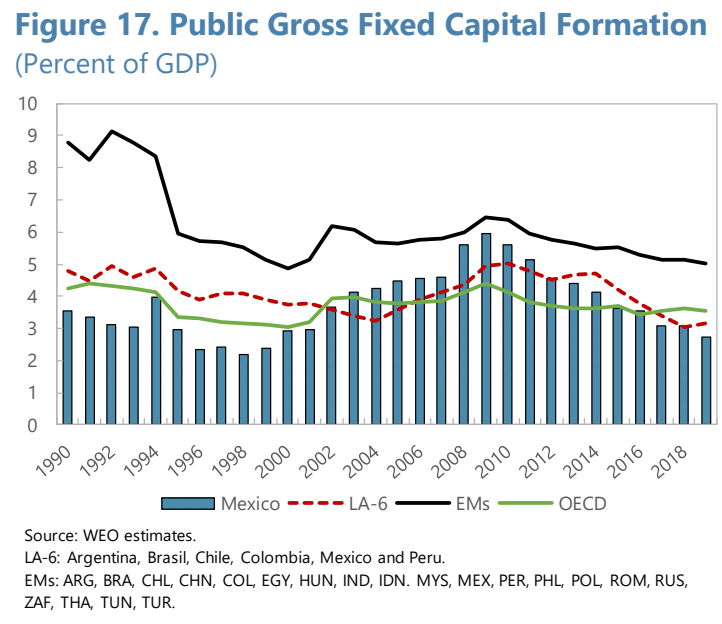

Figure 17. Public Gross Fixed Capital Formation (Percent of GDP)

2008-2018, on average, to $2 \frac{1}{2}$ percent in 2019. Capital spending in Mexico is also lower than regional and EM peers and OECD countries. . Consequently, the proposed package includes an increase of public investment of around 1 percent of GDP in the medium-term (excluding investing in healthcare; see below) to bring the ratio in line with historical averages and that of peers. 
Health spending. As computed in IMF (2019a), an increase in health spending of $1 / 2$ percent of GDP is needed over the medium-term to make satisfactory progress towards the Sustainable Development Goals (SDGs) in health by 2030. The costing exercise follows the input-output methodology of Gaspar and others (2019) in: (i) identifying key inputs and their corresponding costs in the health sector; (ii) benchmarking input costs in Mexico to that of countries with comparable income per capita but higher current social outcomes; and (iii) estimating the spending levels required to achieve those outcomes, conditional on Mexico's income per capita and population growth. IMF (2019a) finds that Mexico could increase the share of doctors in the population and their wages but contain the number of other health professionals. It must also be noted that the spending to achieve SDG goals would be considerably larger if efficiency gains are not achieved. This is probably a conservative estimate given the likely long-lasting effects of the Covid-19 shock.

\section{Strengthen Social Safety Nets and Unemployment Insurance}

In response to the Covid-19 shock, the need for emergency lifelines would be sizable, albeit lower-all else being equal-for countries with stronger unemployment benefits and social safety nets (SSN). ${ }^{13}$ Given the lack of a nationwide unemployment benefits system in Mexico and the likely adverse impact of the pandemic on poverty and inequality for years to come, there is a need to strengthen SSNs durably. An enhanced SSN can also protect the most vulnerable from unintended consequences of proposed VAT reform.

A good social safety net usually has four attributes (Grosh and others 2008 and IMF 2020b). First, it provides broad coverage and adequate benefits to vulnerable groups in a progressive way within the overall tax-benefit system (IMF 2019b) - that is, more generous benefits to accruing to the poorest beneficiaries. Second, it strives to be cost effective by avoiding program fragmentation and beneficiary overlaps. Third, it aims to preserve work incentives and enhance human capital accumulation by linking transfers to required or voluntary programs such as public works, obtaining health care, and attending education and training. Fourth, it is financially sustainable within the overall expenditure envelope and consistent with other social protection programs.

Against these yardsticks, SSNs in Mexico have significant gaps in terms of coverage of lower income groups and beneficiary incidence - see Figures 18 and 19. The cost of SSNs as a share of GDP is relatively high, in part, reflecting social and political choices made to reduce poverty gaps (Figures 20 and 21). Programs are fragmented, involve beneficiary overlaps, and lack appropriate incentive features (IMF 2019a). Moreover, the burden of income support is placed on SSNs, as very few of the poor are covered by unemployment insurance. SSNs in Mexico can be improved by expanding coverage in a cost-effective manner through proxy-means targeted transfers, whereby targeting is improved by giving

\footnotetext{
${ }^{13}$ Further to the discussion in footnote 6, social safety nets are noncontributory transfer programs aimed at lowincome households or the vulnerable (World Bank 2018; IMF 2020b). They are financed through government revenues and usually comprise (i) cash transfers, food stamps, child allowances, and social pensions; (ii) in-kind transfers; (iii) conditional transfers; (iv) public works; and (v) fee waivers, including for health care.
} 
households a score based on a statistical algorithm that predicts incomes or consumption or poverty (see Coady and Le 2020 for details), and decreasing duplications as the country strengthens its administrative capacity. The relatively large leakage of benefits to higherincome groups in Mexico increases the importance of better targeting as well as strengthening progressive income taxes to claw back these benefits from high-income groups. Mexico can also use instruments that are effective in reaching individuals most in need, including in the informal sector. These instruments include mobile money, in-kind transfers such as education and health, matching different databases of beneficiaries to create a single registry, and use of community-based methods to identify those in need. Beyond SSNs, there is scope in designing a nation-wide unemployment benefits system.

\section{Figure 18. Coverage and Adequacy of Social Safety Net Programs by Quintile}

\section{(Percent)}

1. Coverage

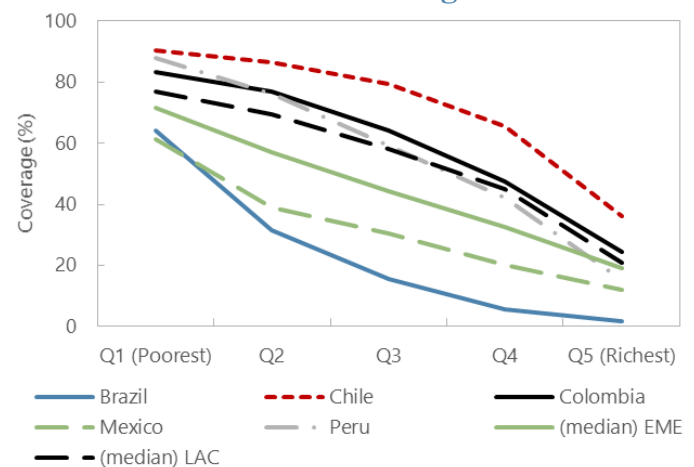

2. Adequacy

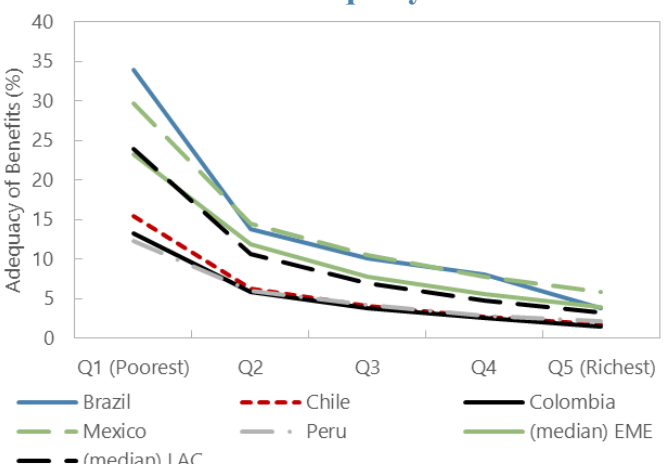

Source: IMF FAD Social Protection \& Labor - Assessment Tool (SPL-AT).

Notes: Coverage measures the percentage of the quintile that receives a SSN benefit. Adequacy of benefits measures the total transfer amount received by all beneficiaries in the quintile as a percent of the pre-transfer total income/expenditure of beneficiaries (in that quintile). Calculations are based on pre-Covid-19 information.

Figure 19. Targeting of Social Safety Net Programs by Quintile (Percent)

1. Benefits Incidence

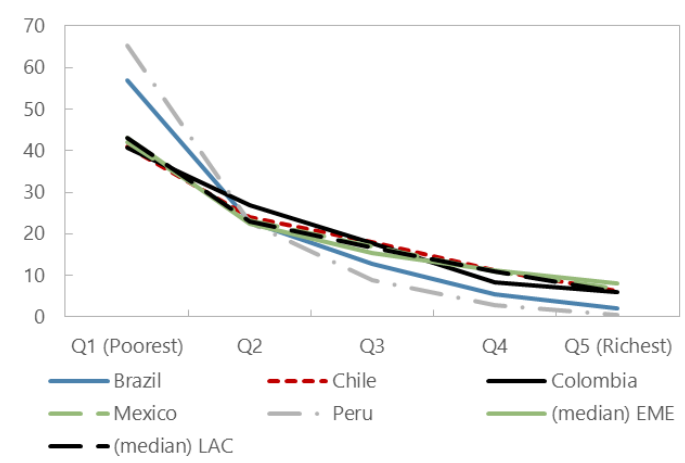

2. Beneficiary Incidence

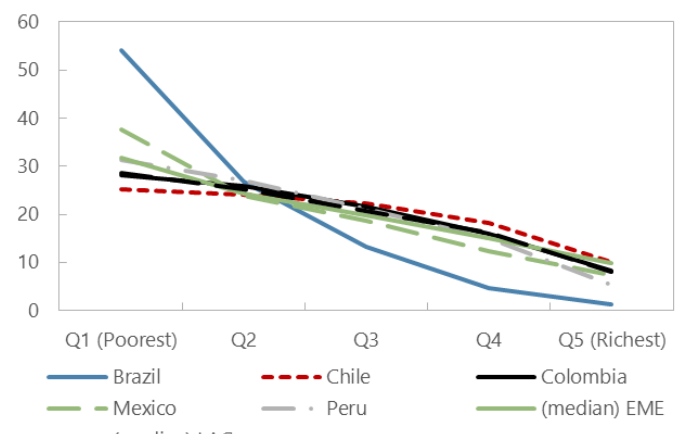

Source: IMF FAD Social Protection \& Labor - Assessment Tool (SPL-AT).

Notes: Benefits incidence measures the percentage of benefits going to each quintile of the pre-transfer welfare distribution relative to the total benefits going to the population. Beneficiary incidence measures the percentage of program beneficiaries in a quintile relative to the total number of beneficiaries in the population. The indicator is estimated by program type and by quintiles of the pre-transfer welfare distribution. Calculations are based on pre-Covid19 information. 


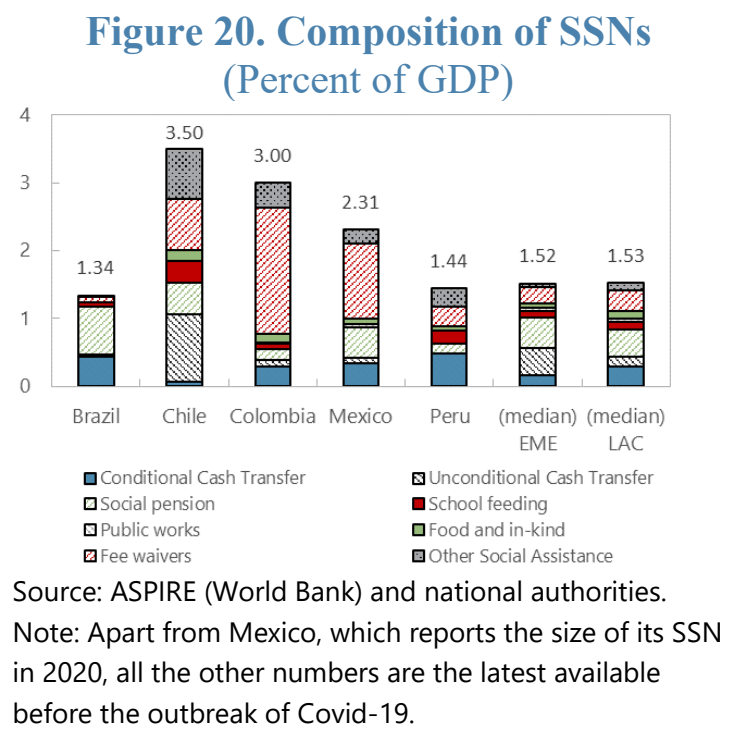

\section{Figure 21. Poverty Reduction Impact of SSNs (Percent of GDP)}

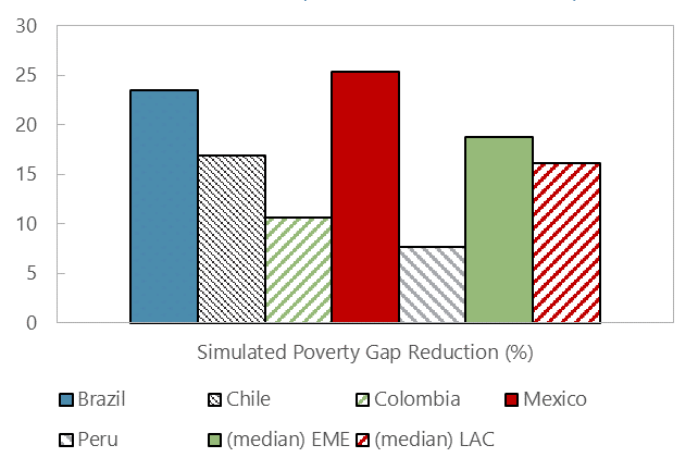

Source: IMF World Economic Outlook.

Note: Simulated percentage change reduction in poverty gap owing to social safety net programs. The calculation is: (poverty gap pre transfer- poverty gap post transfer) / poverty gap pretransfer.

\section{Macroeconomic Impact of the Proposed Package}

This section uses the IMF's Global Integrated Monetary and Fiscal (GIMF) model to illustrate the macroeconomic effects of a "fiscal twist" strategy for Mexico. ${ }^{14}$ GIMF is a multi-country structural dynamic general equilibrium model featuring Mexico, among others. It links the behavior of households, firms, and government sector within and among countries (see Box 2 for details), and is particularly suitable for fiscal policy analysis.

\section{A. The "fiscal twist" package}

Informed by the analysis in Sections II and III, a comprehensive fiscal policy response to Covid-19 and beyond is designed along the following dimensions (summarized in Table 4):

- In the first year, stronger emergency lifelines in response to Covid-19 is assumed:

- Expenditure. Increase of 0.5 percent of GDP in government consumption (largely healthcare); 0.5 percent of GDP in government investment (out of which 0.1 percent of GDP is on healthcare); and 1.2 percent of GDP in targeted social transfers.

○ Revenue. 0.3 percent of GDP in wage subsidies which is reflected in the model as a decline in labor tax.

- Broad-based fiscal support in the second year to facilitate the recovery followed by growth-friendly and inclusive adjustments thereafter (fully anticipated):

\footnotetext{
${ }^{14}$ With the economy re-opening and signs of a recovery underway, use of a standard framework (GIMF) can help unpack the benefits and costs of the proposed package.
} 
- Expenditure. Maintain higher levels of public investment to support the recovery next year and over the medium-term for healthcare (0.5 percent of GDP; to make progress toward the Sustainable Development Goals in health). Enhancing social safety nets would cost about 0.5 percent of GDP. They should support the government's poverty-reduction efforts ( 0.2 percent of GDP) and alleviate the regressive nature of the proposed VAT reform ( 0.3 percent of GDP)..

- Revenue. As a result of the proposed tax reform, revenues would structurally increase by 2.0 percent of GDP from the third year, assuming the pandemic is fully under control by then. This includes broadening of the PIT base and increasing social security contributions ( 0.5 percent of GDP), improving VAT performance (1 percent of GDP), broadening of the CIT base (0.2 percent of GDP), and increasing property/local taxes ( 0.3 percent of GDP). Revenue gains are assumed to be lower than what we identified in Section III in the simulations. The remainder is assumed to close estimated fiscal gaps (in the baseline).

Overall, the above package assumes a $2 \frac{1}{2}$ percent of GDP increase in the overall fiscal deficit in the first year to mitigate the economic fallout from Covid-19 through emergency lifelines. This fiscal support is tapered off in the second year to 1 percent of GDP and its focus is changed from lifelines to facilitating the recovery through long-lasting public investment and stronger social safety nets. A 2 percent of GDP permanent increase in taxes (VAT, corporate and personal income taxes, and lumpsum taxes) is assumed in the third year alongside an additional increase in public investment (1 percent of GDP). Overall, this would result in a neutral-budget package from the third year as the increase in revenues offsets the increase in higher-quality expenditure. This neutral package is assumed above-and-beyond measures to close fiscal gaps that remain in the baseline. Assuming that the medium-term tax reforms are perceived as credible, the package would lower the risk premium by 50 basis points owing to positive confidence effects from the much-needed reforms.

Finally, a scenario is simulated where public investment efficiency is assumed to be 30 percent higher. On average, more than one-third of funds for public infrastructure are estimated to be lost owing to inefficiencies worldwide (IMF 2015; Baum, Mogues, and Verdier 2020). Mexico is no exception to this problem and to increase the long-term output gains from increased public investment, efficiency needs to be improved. Sound institutional processes, including careful project selection, management, and evaluation, as well as a clear delineation of responsibilities and mechanisms to ensure coordination between central and subnational governments, should be in place to ensure productive investment (IMF 2015). 
Table 4. Model Inputs for GIMF Simulation

(In percent of January 2020 WEO GDP)

\begin{tabular}{|c|c|c|c|c|c|c|}
\hline & $t=1$ & 2 & 3 & 4 & 5 & 6 \\
\hline Government deficit (expenditure-revenue) & 2.5 & 1.0 & 0.0 & 0.0 & 0.0 & 0.0 \\
\hline Total expenditure & 2.2 & 1.0 & 2.0 & 2.0 & 2.0 & 2.0 \\
\hline Government consumption $1 /$ & 0.5 & & & & & \\
\hline Government investment & 0.5 & 0.5 & 1.5 & 1.5 & 1.5 & 1.5 \\
\hline Targeted transfers & 1.2 & 0.5 & 0.5 & 0.5 & 0.5 & 0.5 \\
\hline Total revenue & -0.3 & 0.0 & 2.0 & 2.0 & 2.0 & 2.0 \\
\hline Labor tax (incl. social security contribution) & -0.3 & & 0.5 & 0.5 & 0.5 & 0.5 \\
\hline Consumption tax & & & 1 & 1 & 1 & 1 \\
\hline Corporate Income tax & & & 0.2 & 0.2 & 0.2 & 0.2 \\
\hline Property tax (lumpsum tax) & & & 0.3 & 0.3 & 0.3 & 0.3 \\
\hline Sovereign risk premium (basis point) & -50 & -50 & -50 & -50 & -50 & -50 \\
\hline
\end{tabular}

1/ Health spending classified as part government consumption, part government invesment.

\section{Box 2. The Global Integrated Monetary and Fiscal Model (GIMF)}

The IMF's Global Integrated Monetary and Fiscal (GIMF) model is used to quantify the effects of the fiscal package — see Kumhof and others (2010) and Anderson and others (2013) for more details.

GIMF is a multi-country structural dynamic general equilibrium model featuring six regions: Mexico, the US, Japan, emerging Asia, euro area, and the rest of the world. It links the behavior of households, firms, and government sector within and among countries. The model has a consistent system of national accounting and stock-flow budget constraints for all sectors, including the government. The model belongs to exogenous-growth types of models, meaning that the long-term growth of output is exogenous. Hence, all fiscal or structural measures may change only the structure of the economy, possibly increasing permanently the level of real output per capita, and not the long-term growth.

The household sector consists of forward-looking optimizing households, as well as liquidityconstrained households who spend all their available income every period. The forwardlooking households are modeled as overlapping generations (OLG) with finite lives, following the Blanchard-Weil-Yaari framework. The presence of OLG households breaks Ricardian equivalence and is important for realistic results of fiscal policy in the short and long runs. Households gain utility from consumption and disutility from labor effort, consume traded and non-traded services and goods, receive labor income, transfers from the government and dividends from corporations, and pay income, consumption and lump-sum taxes.

Firms produce intermediate and final goods using labor and capital inputs and accumulate capital. Firms pay taxes from corporate income. 
The government collects tax revenues (consumption, labor income, capital income, and lumpsum taxes) and spends them on government consumption, investment, and lump-sum transfers to either all or targeted to liquidity-constrained households. It targets a specific debt-to-GDP (and thus deficit-to-GDP) ratio and uses a mix of instruments to achieve it. The government's commitment to sustainable public finance is credible for firms and households, who hold the stock of government bonds.

Fiscal policy is conducted using a variety of expenditure and tax instruments. Beside the afore-mentioned instruments, the model also allows for tariffs on imported goods to be a potential source of public revenue. Government investment spending augments public infrastructure, which depreciates at a constant rate over time.

There is a fiscal policy rule that ensures long-run sustainability, while allowing for short-run counter-cyclical policies. Changes in labor and capital income taxes provide the instruments to put the rule into effect, but this can be replaced with other tax, transfer or spending instruments if that is considered more realistic for a specific region. First, the fiscal rule ensures that, in the long run, the ratio of the government debt-to-GDP - and hence the deficitto-GDP ratio- eventually converges to its target level. This excludes the possibility of sovereign default, as well as the risk that out-of-control financing requirements of the government will override monetary policy. Second, the rule allows for countercyclical fiscal policy as it embodies automatic stabilizers.

When conducting monetary policy, the central bank uses an inflation-forecast-based interest rate rule. The central bank varies the gap between the actual policy rate and the long-run equilibrium rate to achieve a stable target rate of inflation over time.

\section{Calibration}

The calibration of the parameters of the household utility function, elasticities and markups are the same across countries. The shares of liquidity-constrained agents in the population are 50 percent for Mexico, Emerging Asia and the remaining countries and 25 percent for other regions. Country specific data are used for great ratios based on the most recent year or some average (all in percent of GDP). Key variables include private investment share, government consumption, public investment, fiscal variables including tax revenue, government debt, share of different taxes in GDP (consumption tax, labor and corporate income tax), and labor

\begin{tabular}{|l|c|}
\hline \multicolumn{2}{|c|}{ Mexico: Key Calibration Parameters } \\
(Percent) & 3.0 \\
\hline Inflation & 50 \\
Share of liquidity constraned households & 15.7 \\
Government consumption/GDP & 1.3 \\
Net acquisition of nonfinancial assets/GDP & 18.6 \\
Private investment/GDP & 5.4 \\
Government transfer/GDP & 15.4 \\
Tax and SSCs revenue/GDP & 5.6 \\
Labor tax incl. SSCS/GDP) & 5.8 \\
Consumption tax (\% GDP) & 3.6 \\
CIT revenue (\% GDP) & 0.5 \\
Property and other taxes/GDP & 8.7 \\
Other revenue/GDP & 53.7 \\
Gross public debt/GDP &
\end{tabular}
shares. In addition, bilateral trade flows between regions and each region's share of world population are essential in accounting for spillover effects. The monetary policy parameters are calibrated based on estimation results of reaction functions for an annual model. 


\section{B. Model Results}

We present the macroeconomic effects of the "fiscal twist" package compared to the January 2020 WEO baseline in three blocks: (i) expenditure measures; (ii) the total package, including the expenditures measures, tax reforms, and 50 bps decline in risk premia; and (iii) the total impact assuming continued monetary accommodation so long as inflation expectations remain anchored and demand shortages persist. ${ }^{15}$ Furthermore, the results with the increase in public investment efficiency are presented (Figure 23). Note that the Covid-19 shock has already resulted in a sharp GDP contraction in 2020 with expectation of a gradual economic recovery over the medium term. The payoffs from the "fiscal twist" package (presented below) would, therefore, only be able to restore a part of the GDP fall.

The expenditure measures are expected to increase the level of GDP by 1.2 percent in the first year, and, over the medium-term, by 2 percent. Increased demand within the economy is expected to appreciate the real exchange rate and deteriorate the current account balance. The overall budget deficit would increase according to the size of spending increases in Table 4. Without any concomitant reforms to boost

Figure 22. Macroeconomic Effects of the Fiscal Package
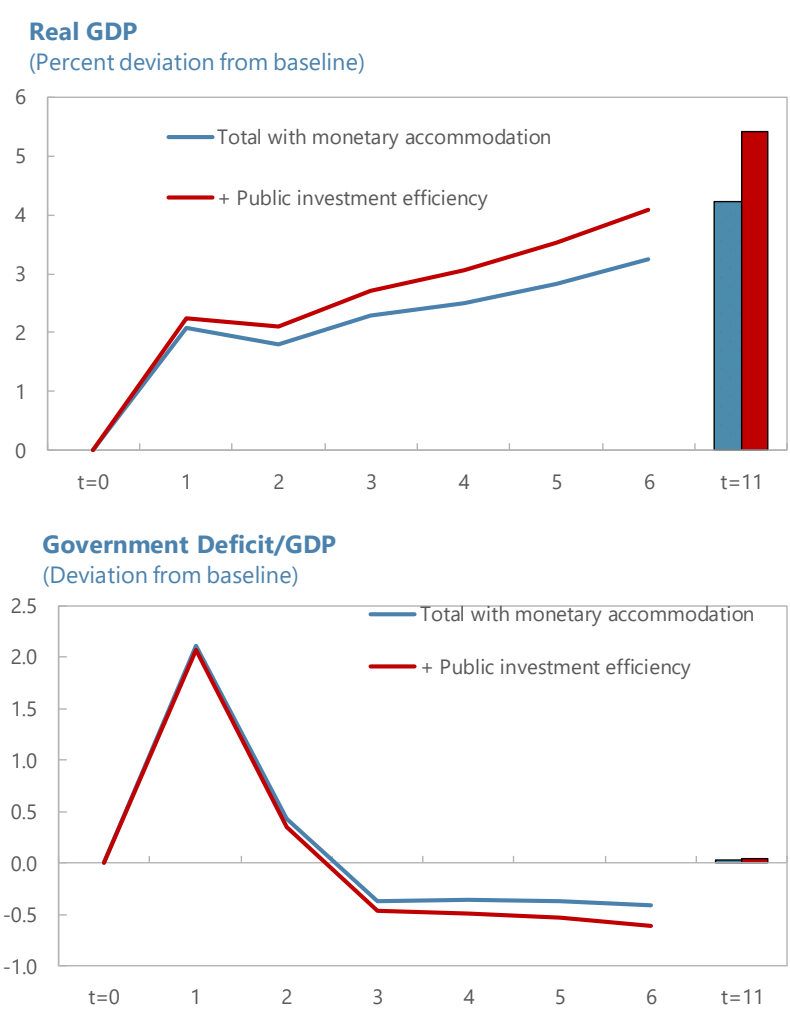

Government Net Debt/GDP

(Deviation from baseline)

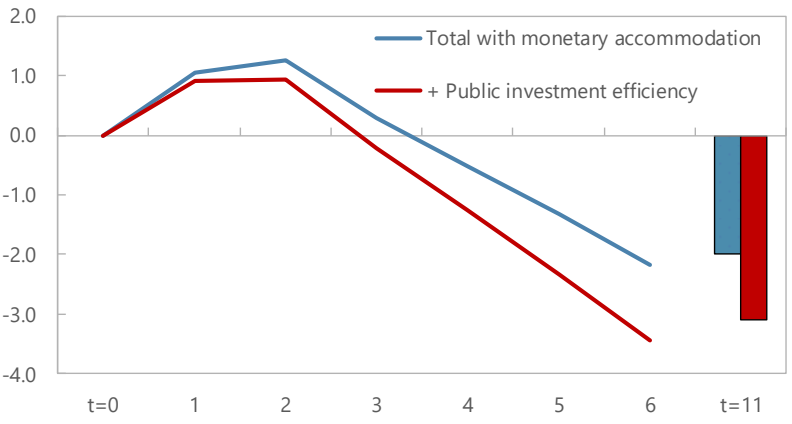

revenues, public debt would increase by 9 percentage points of GDP in the medium term.

Combining the expenditure measures with a credible tax reform (including risk premia reductions) would lead to output gains as well as a stable public debt path (assuming no additional monetary accommodation). The level of GDP would be higher relative to the

\footnotetext{
${ }^{15}$ Estimates from the empirical literature inform the multipliers assumptions in GIMF. See IMF 2020c for details on multiplier estimates by instrument.
} 
January 2020 WEO baseline in the first year as a result of larger emergency lifelines. Following a dip in the second year as fiscal support is partially withdrawn, output is expected to continue to increase by about 3.6 percent in the long run (in eleven years). The real exchange rate is expected to appreciate in the first few years owing to the increased domestic demand, but eventually depreciate as the tax reforms are enacted. The effect of domestic demand and the real exchange rate would deteriorate current account initially but then improve over the medium term. The government deficit will increase in the first year and then gradually decrease.

The overall positive effect on GDP and public debt trajectory is greater when monetary authorities do not react to the higher fiscal deficits by raising interest rates so long as inflation expectations remain well anchored and demand shortages persist (i.e., the Central Bank could remain accommodative within its mandate). In the medium term, the output could increase by 3.2 percent, government deficit could fall 0.4 percentage points, and government debt could fall by 2.2 percentage points. Finally, the increase in investment efficiency would be further beneficial, with output improving by 4.1 percent, government deficit falling by 0.6 percentage points, and government debt declining by 3.5 percentage points over the medium term. The gains from improvements in the composition of fiscal policy mix and the fiscal twist are sizable. Coupled with structural reforms to improve productivity growth, the overall benefits would be very significant over the medium term. 
Figure 23. Impact of Proposed Fiscal Package
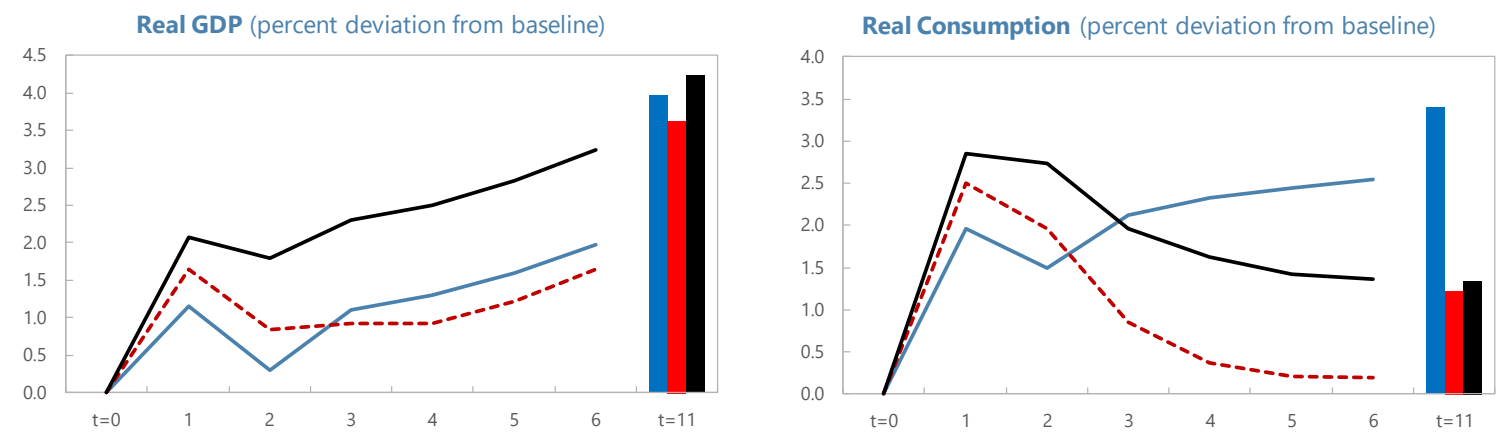

Real Investment (percent deviation from baseline)

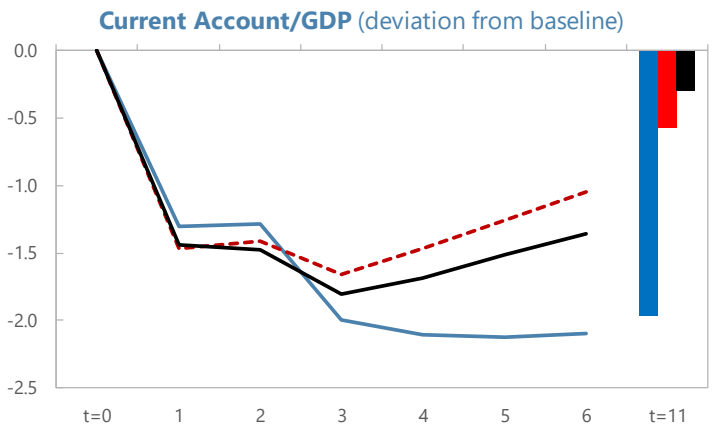

Real Effective Exchange Rate

(percent deviation from baseline; +ve=appreciation)

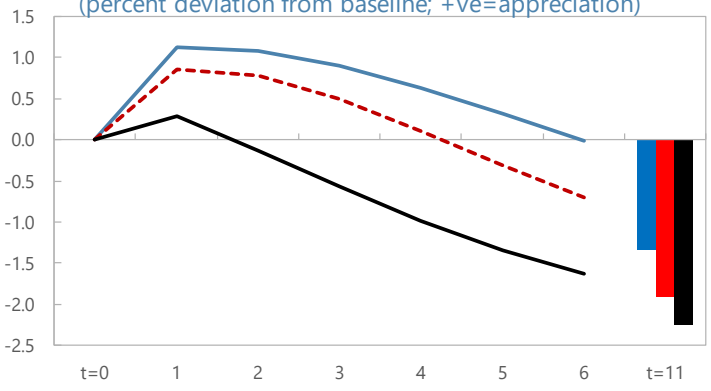

Interest Payments/GDP (difference from baseline)

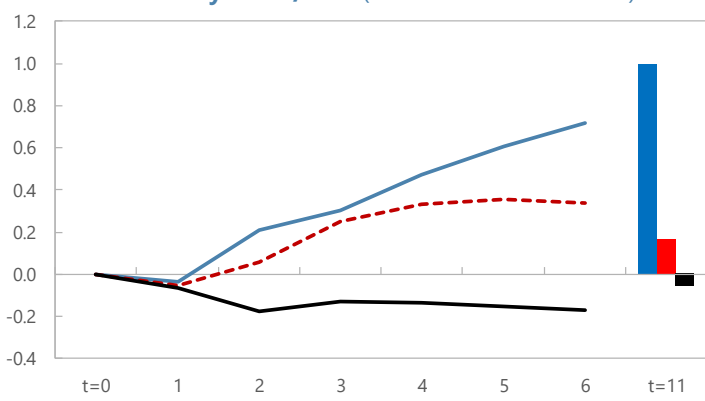

Government Deficit/GDP (difference from baseline)

Government Net Debt/GDP

(difference from baseline)
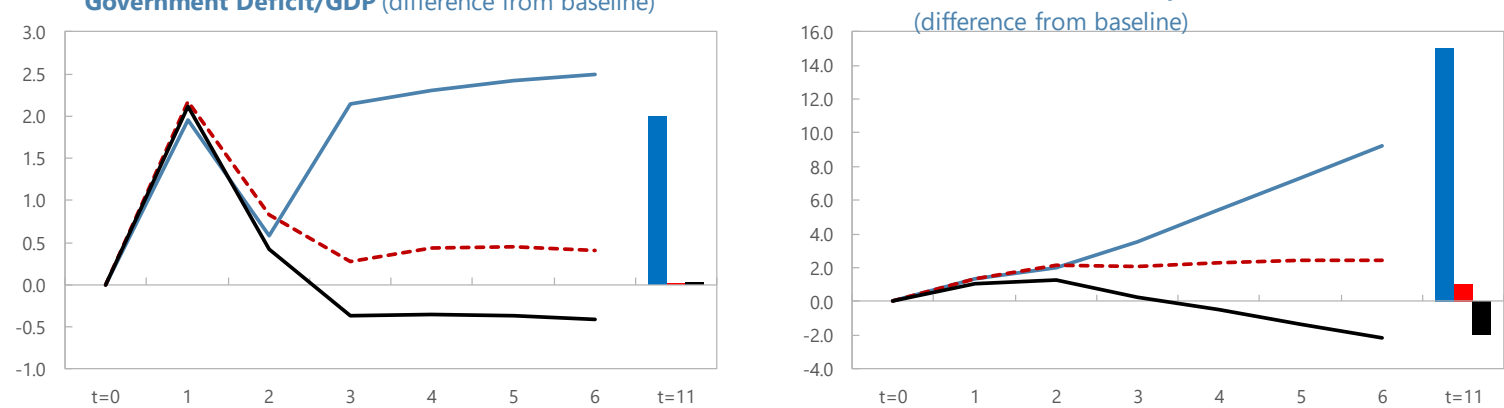

- Expenditure

- - - Total 


\section{Conclusion}

Mexico needs to contain the pandemic, mitigate its economic effects, facilitate a rapid recovery, and rebuild fiscal buffers over the medium term. Fiscal policy is an important lever to meet these goals. Fiscal resources are needed in the near term to accommodate additional spending on healthcare and emergency services as well as to protect people and viable firms through timely, targeted and temporary lifelines. In the near term, the paper estimates that a fiscal support of around 2.5-3.5 percent of GDP would be required in health spending, social safety nets, wage subsidies, and public investment.

Given that social spending are projected to increase over time and other expenditure pressures are emerging in Mexico (including the need for higher public investment), raising revenues from their current exceptionally low levels is indispensable to finance them sustainably. A higher revenue envelope could also create fiscal space for a more forceful near-term Covid-19 response. The paper proposes a tax reform of at least 3 percent of GDP, centered on policy and administration actions that could improve VAT performance, rationalize inefficient and regressive income tax expenditures, and widen the top personal income tax bracket. This reform should be paired with enhanced social safety nets.

Using IMF's GIMF model, simulations suggest that the proposed "fiscal twist" package would substantially increase output in the medium term and put public debt on a firm declining path compared to their January 2020 WEO path. Higher investment efficiency would further bolster these effects. While the focus of the paper is on fiscal policies, supportive stances in monetary and other policies would be required for a durable economic recovery. 


\section{REFERENCES}

Alvarez, J. and C. Ruane, 2019, "Informality and Aggregate Productivity: The Case of Mexico,” IMF Working Paper WP/19/257 (Washington: International Monetary Fund).

Anderson, D., B. Hunt, M. Kortelainen, M. Kumhof, D. Laxton, D. Muir, S. Mursula, and S. Snudden, 2013, "Informality and Aggregate Productivity: The Case of Mexico Getting to Know GIMF: The Simulation Properties of the Global Integrated Monetary and Fiscal Model," IMF Working Paper WP/13/55 (Washington: International Monetary Fund).

Barrero, Jose Maria, Nicholas Bloom, and Steven J. Davis. 2020. "COVID-19 Is Also a Reallocation Shock.” NBER Working Paper 27137, National Bureau of Economic Research, Cambridge, MA.

Baum, Anja, Tewodaj Mogues, and Genevieve Verdier. 2020. "Getting the Most from Public Investment." In Infrastructure Governance: From Aspiration to Action, edited by Gerd Schwartz, Manal Fouad, Torben Steen Hansen, and Genevieve Verdier. Washington, DC: International Monetary Fund.

Chudik, Alexander, Kamiar Mohaddes, M. Hashem Pesaran, Mehdi Raissi, and Alessandro Rebucci. 2020. "A Counterfactual Economic Analysis of Covid-19 Using a Threshold Augmented Multi-Country Model.” NBER Working Paper 27855, National Bureau of Economic Research, Cambridge, MA.

Chudik, Alexander, Kamiar Mohaddes, M. Hashem Pesaran, and Mehdi Raissi. 2017. "Is There a Debt-Threshold Effect on Output Growth?" The Review of Economics and Statistics 99 (1): 135-50.

Coady, D. and N. Le, 2020. "Designing Fiscal Redistribution: The Role of Universal and Targeted Transfers”, IMF Working Paper WP/20/105 (Washington: International Monetary Fund).

Deb, Pragyan, Davide Furceri, Jonathan D. Ostry, and Nour Tawk, 2020. “The Economic Effects of COVID-19 Containments Measures”, IMF Working Paper WP/20/158 (Washington: International Monetary Fund).

Dudine, P., K. Hellwig, and S. Jahan, 2020. “A Framework for Estimating Health Spending in Response to COVID-19", IMF Working Paper Series, WP/20/145 (Washington: International Monetary Fund).

Kumhof, M., D. Laxton, D. Muir and S. Mursula, 2010, “The Global Integrated Monetary Fiscal Model (GIMF) —Theoretical Structure," IMF Working Paper Series, WP/10/34 (Washington: International Monetary Fund).

Gaspar, V., D. Amaglobeli, M. Garcia-Escribano, D. Prady, and M. Soto, 2019. Fiscal Policy and Development: Human, Social, and Physical Investments for the SDGs. International Monetary Fund.

Grosh, Margaret E., Carlo Del Ninno, Emil Tesliuc, and Azedine Ouerghi. 2008. For Protection and Promotion: The Design and Implementation of Effective Safety Nets. Washington, DC: World Bank. 
International Monetary Fund (IMF) 2015. "Making Public Investment More Efficient." IMF Policy Paper, Washington, DC.

IMF 2017. "Mexico Revenue Administration Gap Analysis Program- The Value-Added Tax Gap", Technical Assistance Report, May 2017.

IMF 2018. "Mexico: Evaluación del Desempeño y Nivel de Cumplimiento del IVA". Reporte de Asistencia Técnica.

IMF 2019a. "Mexico: Budgetary Spending Pressures", Mexico: Selected Issues, IMF Country Report No. 19/337, International Monetary Fund.

IMF 2019b. "A Strategy for IMF Engagement on Social Spending." IMF Policy Paper 19/016, Washington, DC.

IMF 2019c. "Mexico: 2019 Article IV Consultation Staff Report", IMF Country Report No. 19/336, International Monetary Fund.

IMF 2020a. "October 2020 Regional Economic Outlook: Western Hemisphere — Fiscal Policy at the Time of a Pandemic: How has Latin America and the Caribbean Fared?" International Monetary Fund, Washington, DC.

IMF 2020b. "Fiscal Monitor: Policies to Support People During the COVID-19 Pandemic." Fiscal Affairs Department, International Monetary Fund, Washington DC, April 2020.

IMF 2020c. "Managing the Impacts of the Coronavirus: Guidance on Health Spending Policies." Special Series on Fiscal Policies to Respond to COVID-19: https://www.imf.org/ /media/Files/Publications/covid19-special-notes/enspecial-serieson-covid19managing-the-impacts-of-the-coronavirus-guidance-on-health-spendingpolic.ashx?la=en.

IMF 2020d. "October 2020 Regional Economic Outlook: Western Hemisphere - Covid-19 in Latin America and the Caribbean-A High Toll on Lives and Livelihoods?" International Monetary Fund, Washington, DC.

Levy, Santiago. 2018. Under-rewarded efforts: The Elusive Quest for Prosperity in Mexico. Inter-American Development Bank. https://flagships.iadb.org/en/Under-RewardedEfforts.

Parr 2020. "COVID-19 Data Analysis, Part 5: Different Models of Infection Rates in Mexico and What they Tell Us." https://dai-global-digital.com/covid-19-part-5-differentmethods-to-model-infection-rates-in-mexico-and-what-they-tell-us.html

World Bank 2018. The State of Social Safety Nets 2018. Washington, DC: World Bank. Zavala, M. R. and L. Despeghel, 2020. “¿Qué nos dicen las actas de defunción de la CDMX? Actualización al 23 de agosto 2020”, Nexos. https://datos.nexos.com.mx/?p=1657 